\title{
Coupling a new turbulence parametrization to RegCM adds realistic stratocumulus clouds
}

\author{
T. A. O'Brien ${ }^{1,{ }^{*} \text {, P. Y. Chuang }}{ }^{1}$, L. C. Sloan ${ }^{1}$, I. C. Faloona ${ }^{2}$, and D. L. Rossiter ${ }^{1}$ \\ ${ }^{1}$ University of California, Santa Cruz, Department of Earth and Planetary Sciences, Santa Cruz, California, USA \\ ${ }^{2}$ University of California, Davis, Department of Land, Air, and Water Resources, Davis, California, USA \\ *now at: Lawrence Berkeley National Lab, Berkeley, California, USA
}

Correspondence to: T. A. O’Brien (taobrien@lbl.gov)

Received: 13 October 2011 - Published in Geosci. Model Dev. Discuss.: 9 December 2011

Revised: 6 July 2012 - Accepted: 11 July 2012 - Published: 3 August 2012

\begin{abstract}
To model stratocumulus clouds in the regional climate model, RegCM4.1, the University of Washington (UW) turbulence parametrization has been coupled to RegCM. We describe improvements in RegCM's coastal and near-coastal climatology, including improvements in the representation of stratiform clouds. By comparing output from a 27-yr (19822009) simulation of the climate of western North America to a wide variety of observational data (station data, satellite data, and aircraft in situ data), we show the following: (1) RegCM-UW is appropriate for use in general regional climate studies, and (2) the UW model distinctly improves the representation of the marine boundary layer in RegCM. These model-data comparisons also show that RegCM-UW has a slight cold bias, a (wet) precipitation bias, a systematic low bias in the vertically-integrated liquid water content near the coast, and a high bias in the fractional cloud coverage. The model represents well the diurnal, monthly, and interannual variability in low clouds. These results show RegCMUW as a nascent mesoscale stratocumulus model that is appropriate for stratocumulus investigations at scales ranging from hourly to decadal. The source code for RegCM-UW is publicly available, under the GNU license, through the International Centre for Theoretical Physics.
\end{abstract}

\section{Introduction}

Low-lying stratocumulus clouds, occurring near the top of the atmospheric boundary layer, are a dominant feature of the atmosphere near western coasts. Marine stratocumulus clouds (MSc) are a particularly important class of cloud because globally, MSc increase the planetary albedo by covering the low-albedo ocean with high-albedo clouds that emit long-wave radiation at a rate comparable to that of the ocean (Klein and Hartmann, 1993). Regionally, MSc (and associated coastal fog) moderate coastal temperatures and are an important source of moisture for coastal ecosystems (Koračin et al., 2001; Dawson, 1998). The climatological importance of MSc, and the myriad ways that anthropogenic climate change might affect them, has made them the topic of a number of recent studies (e.g. Meehl et al., 2007; Stevens and Feingold, 2009; Park and Bretherton, 2009) and has prompted the improvement of global climate models (GCMs) in recent years.

Martin et al. (2000) improved the simulation of cloudtopped boundary layers in the Hadley Centre global model by implementing the parameterization of Lock et al. (2000), which uses a separate diffusivity profile for the clear and cloudy portions of the boundary layer. Köhler (2005) implemented a flux-decomposition approach with a special treatment of the stratocumulus to shallow cumulus transition in the European Centre for Medium-Range Weather Forecast global model; in one case, this improvement added stratocumulus clouds where they had previously been missing, and it generally increased (improved) the amount of liquid water in low clouds. Bretherton and Park (2009) implemented a new moist turbulence paramterization and a new shallow cumulus parameterization into the Community Atmosphere Model; Park and Bretherton (2009) demonstrate that this addition reduces the overall climate bias of the model relative to the original model. These improvements to the representation of low clouds in GCMs are critical for understanding 
how climate might change in the future, given that "cloud feedbacks... have been confirmed as the primary source of climate sensitivity differences" in climate model simulations (Meehl et al., 2007). Lauer et al. (2010) have demonstrated that regional climate models (RCMs) can provide a valuable, additional modeling framework in which to study MSc and their sensitivity to climate.

Regional climate models (RCMs) have increasingly been used to study climate change (e.g. Snyder et al., 2003; Leung et al., 2004; Kueppers et al., 2005; Steiner et al., 2006), yet there have been very few RCM studies that investigate possible changes in MSc resulting from anthropogenic climate change. There is a lack of such studies because most RCMs are incapable of simulating MSc; only a few recent studies have shown improvements in RCMs that render them able to simulate MSc. Bretherton et al. (2004a) and McCaa and Bretherton (2004) coupled the moist turbulence parametrization of Grenier and Bretherton (2001) (hereafter referred to as the "UW" turbulence parametrization) to the National Center for Atmospheric Research (NCAR) Mesoscale Model 5 (MM5). These studies show that coupling the UW model to MM5 improves simulation of MSc relative to the other turbulence parametrizations available in MM5. Additionally, Wang et al. (2004a,b) and Lauer et al. (2009) demonstrate that the recently-developed International Pacific Research Center (IPRC) regional climate model is capable of simulating MSc (the IPRC model uses an E- $\epsilon$ turbulence closure parametrization, which differs completely from that used by Grenier and Bretherton, 2001). Wang et al. (2005) used the IPRC model to investigate the climatological impact of MSc on atmospheric circulation, and Lauer et al. (2010) used the IPRC model to show that global warming may reduce MSc coverage. Wyant et al. (2010) show that the Weather and Regional Forecasting (WRF) model, depending on its configuration, can reasonably reproduce the cloud fraction and boundary layer fields height observed in October 2006, though it tends to underestimate the mean and the diurnal cycle of cloud liquid water path. In an intercomparison of various atmospheric models, Wyant et al. (2010) demonstrate that this level of performance is common for state-of-the-art regional climate models, global climate models, and operational forecast models alike.

The International Centre for Theoretical Physics' RCM, RegCM, is a powerful tool for the RCM community both because it is freely available under the GNU license and because it has a broad international group (the RegCNET) that supports its use (Pal et al., 2007; Giorgi et al., 2012). Unfortunately, RegCM lacks the ability to simulate stratocumulus clouds, and so this widely-used RCM is incapable of being used in studies like that of Wang et al. (2005) and Lauer et al. (2010). To work toward correcting this deficiency, we have coupled the UW turbulence parametrization to RegCM. This manuscript has three main purposes: (1) to demonstrate that RegCM with the UW model has a climatology that compares as well (or better) to observations as the original RegCM,
(2) to demonstrate that the UW model improves the representation of marine boundary layer processes and MSc in RegCM at a wide range of temporal scales, and (3) to show that adding the UW model adds physically realistic stratocumulus clouds to RegCM.

We provide a general description of RegCM 4.1 and the specifics of its coupling to the UW model in Sects. 2 and 3. We show that the long-term climatology of RegCM4.1 with the UW model (RegCM-UW) matches well with a variety of climatological observations over western North America in Sect. 5. A comparison of model output from the default RegCM4.1 and RegCM-UW with in situ data from three stratocumulus field experiments (two from North America and one from South America) shows that the UW model generally improves the physical representation of the marine boundary layer in RegCM; in particular, the UW model adds realistic stratocumulus clouds to RegCM (presented in Sect. 6). We present the climatology of stratocumulus clouds from RegCM-UW, and compare it with satellite-based climatologies in Sect. 7, to show that RegCM-UW simulates well the climatology of stratocumulus clouds at a variety of temporal scales.

\section{Description of RegCM4.1}

The International Centre for Theoretical Physics' regional climate model, RegCM version 4.1 (hereafter referred to as RegCM4.1) is a three-dimensional mesoscale model that is nearly identical to RegCM3 (Pal et al., 2007) in terms of physical parametrizations. Major changes in the model from version 3 to version 4.1 include the following: the inclusion of the Community Land Surface Model v3.5 (CLM3.5) as an optional land surface parametrization, a new optional parametrization for diurnal SST variations, and a major restructuring (modularization) of the code base. RegCM4.1 and its evolution from RegCM3 is fully described in an upcoming special issue of Climate Review (Giorgi et al., 2012), but some salient details are repeated here.

RegCM4.1 treats two types of clouds: convective (subgrid scale) and large-scale. For the stratocumulus region in RegCM, large-scale clouds are dominant. RegCM4.1 treats large-scale clouds in a relatively simple manner, following the work of Pal et al. (2000): any grid cell whose relative humidity is above some threshold (nominally $80 \%$ ) will begin to have fractional cloud coverage. Cloud water, which is a prognostic variable in the model that is advected and diffused, is added to the grid cell in proportion to the cloud fraction. Grid cells with relative humidity above an upper threshold (nominally $101 \%$ ) have maximal fractional cloud coverage. Clouds precipitate when their in-cloud liquid water content exceeds a temperature-dependent threshold. Precipitation is assumed to reach the surface within the model's time step, which is typically on the order of $1-2 \mathrm{~min}$. On descent, a fraction of the auto-converted precipitation accretes with 
cloud water below its origin, and a fraction of the precipitation evaporates into sub-saturated grid cells below the cloud base.

RegCM4.1 uses the CCM3 radiation package (Kiehl et al., 1996), which is a relatively simple one-dimensional radiation model that divides radiation into multiple short and long wavebands and separately considers the transmission, scattering, absorption, and emission (if applicable) of each band. In terms of cloud radiative properties, the cloud liquid water path is calculated from the prognostic liquid water content, and all but the highest (coldest) clouds are assumed to have a mean droplet radius of $10 \mu \mathrm{m}$.

The default boundary layer parametrization is based on the work of Holtslag et al. (1990) and Holtslag and Boville (1993) (hereafter referred to as the "Holtslag model"). The Holtslag model is a non-local first-order, down-gradient diffusion parametrization with an additional term to account for counter-gradient diffusion. Essentially all of the physics of turbulent mixing is contained within the diffusion coefficient. The diffusion coefficient at every height in the model is an empirical function of both surface conditions (surface buoyancy flux and surface stress) and fractional height within the boundary layer. This diffusion parametrization is based on the similarity theory of Troen and Mahrt (1986). Because the diffusivity is only a function of surface conditions, this diffusion parametrization implicitly assumes that the turbulence within the boundary layer is generated entirely from the surface. The model is described as non-local, because the diffusivity at every height is dependent on bulk boundary layer properties (i.e. surface conditions and boundary layer height), and not on the conditions occurring only at that height (the local conditions).

None of the versions of RegCM thus far, including version 4.1, have been capable of simulating MSc; see Sects. 6 and 7.1. The lack of stratocumulus is likely because the Holtslag model only considers surface-related sources of turbulence; it entirely neglects cloud-top radiative cooling as a source of turbulence ${ }^{1}$. Without this source of turbulence, the occurrence of BL clouds over the ocean, with the Holtslag model, will be limited to areas and times where surface-based convection or mechanical mixing is strong enough to transport moisture from the surface above the lifting condensation level (LCL). Without the cloud-top source of turbulence, the clouds will dissipate once the impetus for vertical mixing ceases. In this view, the Holtslag model lacks a crucial connection in the feedback loop that allows stratocumulus clouds to be self-sustaining.

\footnotetext{
${ }^{1}$ To be precise, the radiation parametrization implicitly includes cloud-top radiative cooling, so that cloud-top cooling affects the temperature profile with the Holtslag model. In this sense, cloudtop radiative cooling indirectly affects turbulence in the Holtslag model.
}

\section{UW TCM description and coupling details}

To include the physical processes necessary for maintaining a stratocumulus deck, we have replaced the Holtslag boundary layer model with the more general turbulence closure parametrization ${ }^{2}$ of Grenier and Bretherton (2001) and Bretherton et al. (2004a) (the UW model).

The UW model is a 1.5-order, local, down-gradient diffusion parametrization. While both the Holtslag and UW models parametrize the vertical diffusivities and viscosity as the product of a length scale and a velocity scale, the Holtslag model bases its velocity scale on surface conditions, whereas the UW model uses local turbulent kinetic energy (TKE) to determine the velocity scale. TKE is determined prognostically as the balance of buoyant production/destruction, shear production, dissipation, vertical transport, and horizontal diffusion and advection; the buoyant production term explicitly accounts for production of TKE by cloud-top radiative cooling (it assumes that all of the divergence takes place right at the top of the cloud; Grenier and Bretherton (2001)). The UW TCM also explicitly parametrizes the entrainment process and accounts for enhancement of entrainment by evaporation of cloudy air into entrained air, which is hypothesized to be an important process in the breakup of MSc (e.g. Lilly, 1968; Nicholls and Turton, 1986).

The UW TCM code that is coupled to RegCM4.1 is essentially identical to the code used by Bretherton et al. (2004a) and $\mathrm{McCaa}$ and Bretherton (2004), with two notable exceptions: a different length scale parametrization and a different surface layer parametrization. Bretherton et al. (2004a) set the master length scale (used in the calculation of diffusivities, TKE dissipation, and entrainment) simply as $l=k z$, whereas Grenier and Bretherton (2001) used the Blackadar length scale of $l=k z /(1+k z / \lambda)$, where $\lambda$ is a constant times the $\mathrm{BL}$ height (the constant is a tunable parameter that Grenier and Bretherton, 2001 set as 0.085). Grenier and Bretherton (2001) argue that their length-scale formulation allows the model to maintain a self-similar TKE profile (i.e. the TKE profile maintains a consistent, geometrically similar shape as the boundary layer height changes), consistent with observations, as the boundary layer profile changes; it is not clear from the Bretherton et al. (2004b) study whether this is the case for $l=k z$. We agree with the arguments of Grenier and Bretherton (2001) about the benefits of using the Blackadar length scale, and so we added an option to RegCM4.1 to use either length scale formulation when using the UW

\footnotetext{
${ }^{2}$ Though both the Holtslag and UW models primarily deal with transporting prognostic quantities in the vertical, we distinguish the UW model from a boundary layer scheme, following Bretherton et al. (2004a), because it determines the vertical mixing due to turbulence in areas above the planetary boundary layer as well as within. The Holtslag model remains in the code as an optional alternative to the UW model.
} 
$\mathrm{TCM}^{3}$; we use the Blackadar length scale for these experiments. Also in contrast to Bretherton et al. (2004a), the surface enthalpy, moisture, and momentum fluxes are calculated in the RegCM land surface model, which can be either the Biosphere-Atmosphere Transfer Scheme (BATS) (Dickinson et al., 1993; Giorgi et al., 1993) or CLM3.5 (Oleson et al., 2008; Tawfik and Steiner, 2011).

\section{Description of model domains}

In the following section, the experimental details are described, by domain, for the two domains used in this study: western North America and western South America.

\subsection{Western North America}

All model results shown for western North America (abbreviated WNA) were created with RegCM-UW on a $50 \mathrm{~km}$ horizontal resolution Lambert Conformal Conic grid centered at $37^{\circ} \mathrm{N}, 123^{\circ} \mathrm{W}$; see Fig. 1. The domain center and domain extent were the two main aspects that guided the choice of this domain: it is chosen to have its center over California's coastline and to extend westward sufficiently far to allow development of MSc. The domain's eastward extent is chosen to avoid cutting high topography on the main model outflow boundary, and its latitudinal extent is such that California is well outside of the model's buffer region (shown in Fig. 1). The lateral boundary conditions for this domain are provided by data from the 6-hourly NCEP-DOE Reanalysis 2 (NNRP2) (Kanamitsu et al., 2002), and the sea surface temperatures are provided from the monthly mean National Oceanic and Atmospheric Administration (NOAA) Optimum Interpolation Sea Surface Temperature V2 (OISST) data set $^{4}$ (Reynolds et al., 2002).

Four simulations on the WNA domain are presented: two using the UW model with the Grenier and Bretherton (2001) length scale formulation, and the other two using the Holtslag model. All four simulations on this domain use the BATS land-surface model (Dickinson et al., 1993), and the Grell convection scheme with the Arakawa and Schubert closure assumption (Grell, 1993). The four runs differ in their start date and duration, their vertical resolution, and the boundary layer model. Table 1 summarizes the experiment names and their specific configurations.

Two long simulations (one UW run and one Holtslag run) were run with 23 vertical levels on the WNA domain from 1 June 1982 to 30 November 2009; the first 18 months of

\footnotetext{
${ }^{3}$ Bretherton and Park (2009) also use the Blackadar length scale in the version of the UW TCM that they coupled to the Community Atmosphere Model, which indicates that the Blackadar length scale may be the better choice

${ }^{4}$ NCEP_Reanalysis 2 and NOAA_OI_SST_V2 data provided by the NOAA/OAR/ESRL PSD, Boulder, Colorado, USA, from their Web site at http://www.esrl.noaa.gov/psd/
}

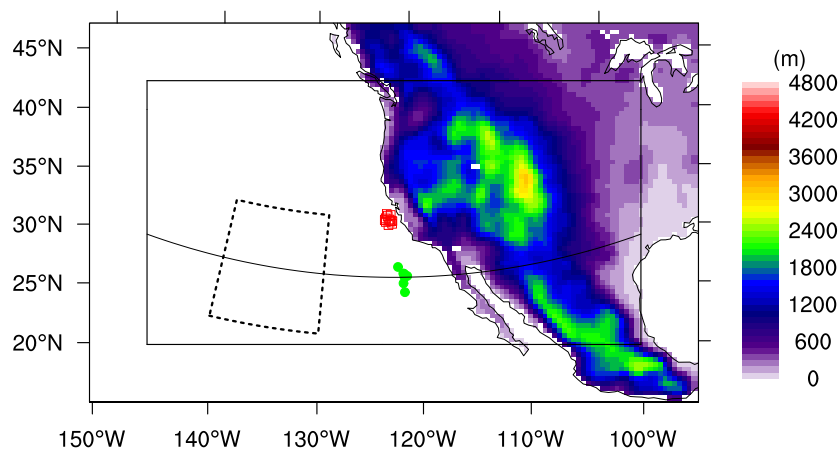

Fig. 1. The topographic height (m) of the western North America (WNA) domain. The solid black box shows the furthest boundary of the buffer zone. The dashed black box shows the area used for averaging in Sect. 7.2, the solid line shows the trace of the transects shown in Sect. 7, and the small red squares and green circles show the locations of field experiments (POST and DYCOMS II, respectively) presented in Sect. 6. All figures on this domain are presented with the buffer zone removed.

simulation are removed to allow for model spin-up. With the spin-up time removed, both runs span exactly 25 model years. All figures that show a climatology use data (or a subset) from one of these two runs; the exact subset of the data depends on the observational data to which the model output are compared. These two runs will be referred to as WNAUW-LONG and WNA-HOLT-LONG, respectively.

Two short simulations (again, one UW run and one Holtslag run) were run with 30 vertical levels on the WNA domain from 1 July 2001 to 31 August 2001. These two simulations are only used for the comparison of model output against data from the Dynamics and Chemistry of Marine Stratocumulus experiment (DYCOMS II), which is presented in detail in Sect. 6. These runs will be referred to as WNAUW-SHORT and WNA-HOLT-SHORT, respectively.

\subsection{Western South America}

For comparison with results from the VAMOS OceanCloud-Atmosphere-Land Study Regional Experiment (VOCALS; described further in Sect. 6, we use the domain shown in Fig. 2, which is centered over western South America (WSA). Two simulations (a UW and a Holtslag run) were run on this domain with $30 \mathrm{~km}$ horizontal resolution and 30 vertical levels, on a Lambert Conformal Conic grid centered at $-20^{\circ} \mathrm{S}, 70^{\circ} \mathrm{W}$. The domain was chosen mainly so that it is centered approximately over the location of the VOCALS flights (shown as an aggregation of black squares off the coast of Peru). The simulations for this domain were started on 1 October 2008 and run through 30 November 2008. The lateral boundary conditions and sea surface temperatures are interpolated from the NNRP2 and OISST data (Kanamitsu et al., 2002; Reynolds et al., 2002). These domains will be 
Table 1. A list of the various RegCM runs used in this study and their relevant parameters.

\begin{tabular}{llllrr}
\hline Domain Abbrev. & Study area & BL model & Run duration & $\begin{array}{r}\text { Horiz. Res. } \\
(\mathrm{km})\end{array}$ & $\begin{array}{r}\text { Vert. Res. } \\
(\# \text { of levels })\end{array}$ \\
\hline WNA-UW-LONG & western North America & UW & Dec 1982-Nov 2009 & 50 & 23 \\
WNA-HOLT-LONG & western North America & Holtslag & Dec 1982-Nov 2009 & 50 & 23 \\
WNA-UW-SHORT & western North America & UW & Jul 2001-Aug 2001 & 50 & 30 \\
WNA-HOLT-SHORT & western North America & Holtslag & Jul 2001-Aug 2001 & 50 & 30 \\
VOCALS-UW & western North America & UW & Oct 2008-Nov 2008 & 30 & 30 \\
VOCALS-HOLT & western North America & Holtslag & Oct 2008-Nov 2008 & 30 & 30 \\
\hline
\end{tabular}

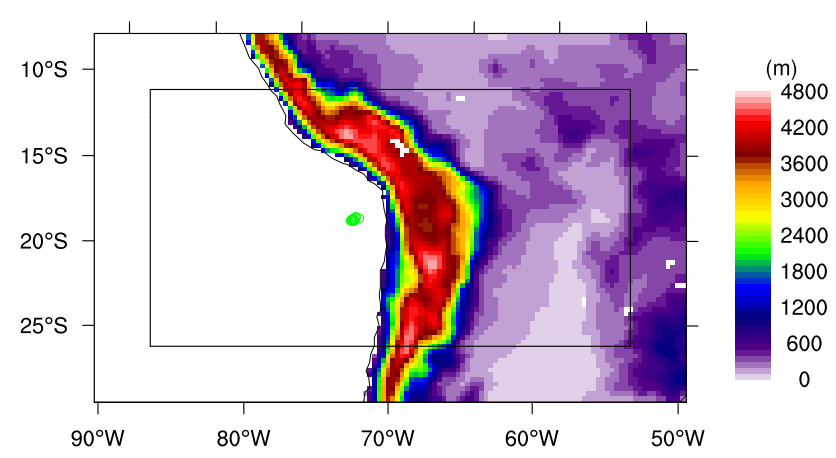

Fig. 2. The topographic height $(\mathrm{m})$ of the western South America (WSA) domain. The inner black box shows the furthest boundary of the buffer zone. The small green circles show flight locations from the VOCALS field experiment, which are presented in Sect. 6

referred to as VOCALS-UW and VOCALS-HOLT (also, see Table 1). Results from these domains are presented in Sect. 6.

\section{Climatology validation}

\subsection{Temperature, precipitation}

By comparing output from RegCM-UW with observational data from several sources, we show that RegCM-UW generally does a good job of simulating the temperature and precipitation climatology of western North America. For validation of the temperature and precipitation climatology over land, we compare RegCM with the CRU TS 3.0 data set (Mitchell and Jones, 2005). The CRU data are an aggregation of station-based observations to a 0.5 -degree resolution grid. For validation of precipitation over the ocean, we use the Global Precipitation Climatology Project (GPCP) v2.1 $1^{5}$ data set. The GPCP precipitation data are a combination of satellite and rain-gauge measured precipitation rates, averaged by month from 1979 to 2009 onto a $2.5 \times 2.5$ degree grid (Adler et al., 2003); the data set was developed by the

\footnotetext{
${ }^{5}$ GPCP data provided by the NOAA/OAR/ESRL PSD, Boulder, Colorado, USA, from their Web site at http://www.esrl.noaa.gov/ psd/
}

NASA/Goddard Space Flight Center's Laboratory for the Atmospheres as a contribution to the GEWEX Global Precipitation Climatology Project.

The wet season temperatures (Fig. 3a and c) tend to be low with the UW model over much of the WNA domain, though the cold bias is typically less than about $4 \mathrm{~K}$ (it is $2.5 \mathrm{~K}$ on average). More importantly for the success of simulating MSc, however, is that the dry season temperatures (Fig. 3b and d) agree well with the CRU data. The model exhibits a slight cold temperature bias during the dry season, though it is limited to less than $2 \mathrm{~K}$ over most of the domain (it is $0.6 \mathrm{~K}$ on average). The temperature biases for the HOLT run are similar in spatial pattern to those shown in Fig. 3, though they are smaller on average: a $1.0 \mathrm{~K}$ cold bias for the wet season, and a $0.02 \mathrm{~K}$ cold bias for the dry season. Initial tests with RegCM-UW showed that it tended to produce a severe cold bias in all seasons. Investigation of this cold bias revealed that the land surface albedos in the BATS model were systematically too high compared with MODIS data (comparison of temperature profiles between the Holtslag and UW models during stable conditions (not shown) suggests that relatively strong mixing during stable conditions tends to mask this problem when using the Holtslag model). Using a version of the procedure described by O'Brien et al. (2012), we adjusted the land surface albedos so that they approximately match those from MODIS. However, this adjustment was done during the early stages of developing the technique described in O'Brien et al. (2012); after the runs for this study were complete, we discovered an issue in the albedo adjustment algorithm that tended to keep the surface albedo values higher than in MODIS (though it still lowers them relative to the original albedos). While the albedo values for the WNA runs shown in this manuscript are lower than the original albedos, and the temperature bias is strongly reduced relative to runs with the original albedos, application of the corrected adjustment algorithm will lower the albedos further. We did not rerun the WNA runs because of computational cost, but we anticipate that correct application of the O'Brien et al. (2012) adjustment algorithm will lower the slight cold biases shown in Fig. $3 \mathrm{c}$ and $\mathrm{d}$.

Figure 4 shows the precipitation climatology for the wet and dry seasons, and the corresponding difference compared 


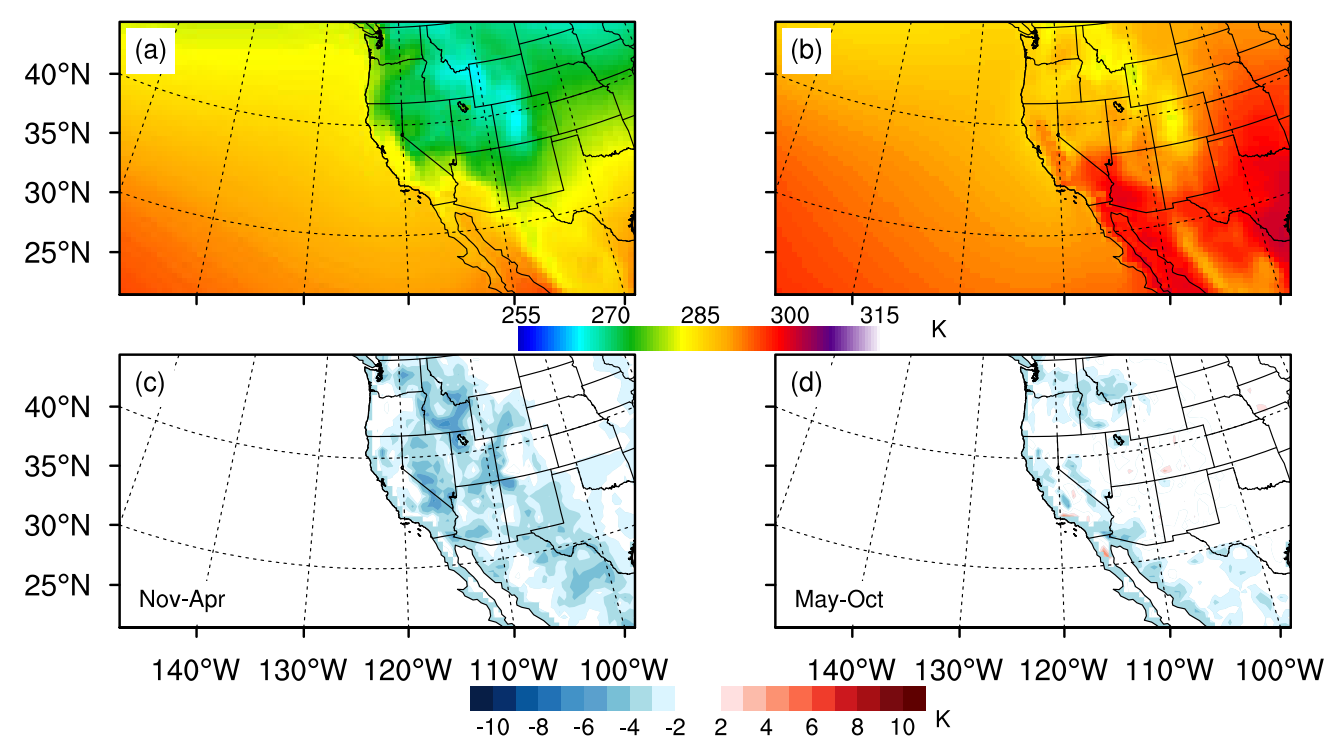

Fig. 3. Near-surface temperature climatology in RegCM-UW (top row), and difference (MODEL-OBS) relative to the Climate Research Unit (CRU) TS3.0 data set (Mitchell and Jones, 2005). The left column shows the wet season average (November-April), and the right column shows the dry season average (May-October): (a) Modeled 2-m temperature wet season average (b) Modeled 2-m temperature dry season average, (c) RegCM-UW wet season temperature bias, and (d) RegCM-UW dry season temperature bias. Differences smaller than $2 \mathrm{~K}$ are shown as white.

to the CRU and GPCP data. The spatial patterns of precipitation for both the wet and dry seasons are similar to the patterns from the CRU and GPCP data, but the model shows a general tendency to overemphasize the rainy areas in the Pacific Northwest. The precipitation bias over the Pacific Northwest is $2-3 \mathrm{~mm} \mathrm{day}^{-1}$ during the wet season, which is $20-100 \%$ too high, depending on the area. During the dry season the precipitation bias is less than $0.5 \mathrm{~mm} \mathrm{day}^{-1}$ (and less than $50 \%$ ) over most of the domain, though it reaches about $1 \mathrm{~mm} \mathrm{day}^{-1}$ (which corresponds to an approximately $100 \%$ bias) in the northern portion. The average precipitation bias over land is $0.6 \mathrm{~mm} \mathrm{day}^{-1}$ for the wet season and $0.3 \mathrm{~mm} \mathrm{day}^{-1}$ for the dry season. For almost all ocean areas in both the wet and dry seasons, RegCM-UW is within $0.5 \mathrm{~mm} \mathrm{day}^{-1}$ of the mean precipitation rates reported in the GPCP data set. These biases are quite similar, in terms of magnitude and spatial pattern, to the biases from the standard version of RegCM, although the average wet season bias is slightly higher (by $0.04 \mathrm{~mm} \mathrm{day}^{-1}$ ), while the dry season bias is slightly lower on average (by $0.02 \mathrm{~mm} \mathrm{day}^{-1}$ ). The use of the UW model and the new land albedos may require retuning of the auto-conversion parametrization to reduce the excessive precipitation in the wet season. Alternatively, we are currently working on implementing the auto-conversion parametrization of Liu et al. (2006) and Liu and Daum (2004) in $\mathrm{RegCM}$ as a way to represent the (warm rain) drizzle process for stratocumulus clouds in a more physically realisticand parametrically constrained-manner. It is possible that this new parametrization may improve the representation of auto-conversion across the whole WNA domain. Either way, further work needs to be done to reduce the high precipitation bias in RegCM-UW.

The UW model improves the representation of interannual variability, both in coastal areas and in strictly inland areas: Fig. 5 shows a Taylor diagram comparing both the UW and Holtslag models with the CRU data. We define coastal areas as land grid cells that have adjacent ocean grid cells, and we define inland areas as land grid cells that are not coastal grid cells (and neither area includes the buffer zone). As explained by Taylor (2001), Taylor diagrams can simultaneously show the correlation ( $r$ ) of a model (RegCM-UW) against a reference data set (CRU and GPCP), the variability of the model compared to the reference data set, and the rootmean squared difference between the model and reference. In Fig. 5, temperature and precipitation are averaged each year for the UW run, the Holtslag run, and the CRU/GPCP data for coastal areas and for inland areas. This produces area-average time-series, with points for each year between December 1984 and November 2005 for both model runs and the CRU/GPCP data. The correlations shown in Fig. 5 are the time-series correlations between the UW run and CRU/GPCP and between the Holtslag run and CRU/GPCP, for three different areas (inland areas, the coast, and the ocean). Similarly, the normalized standard deviations are the ratio of the standard deviations of the time-series between the UW run and CRU/GPCP and likewise for the Holtslag run. Temperatures over the ocean are not shown because SSTs are prescribed in RegCM-UW. 

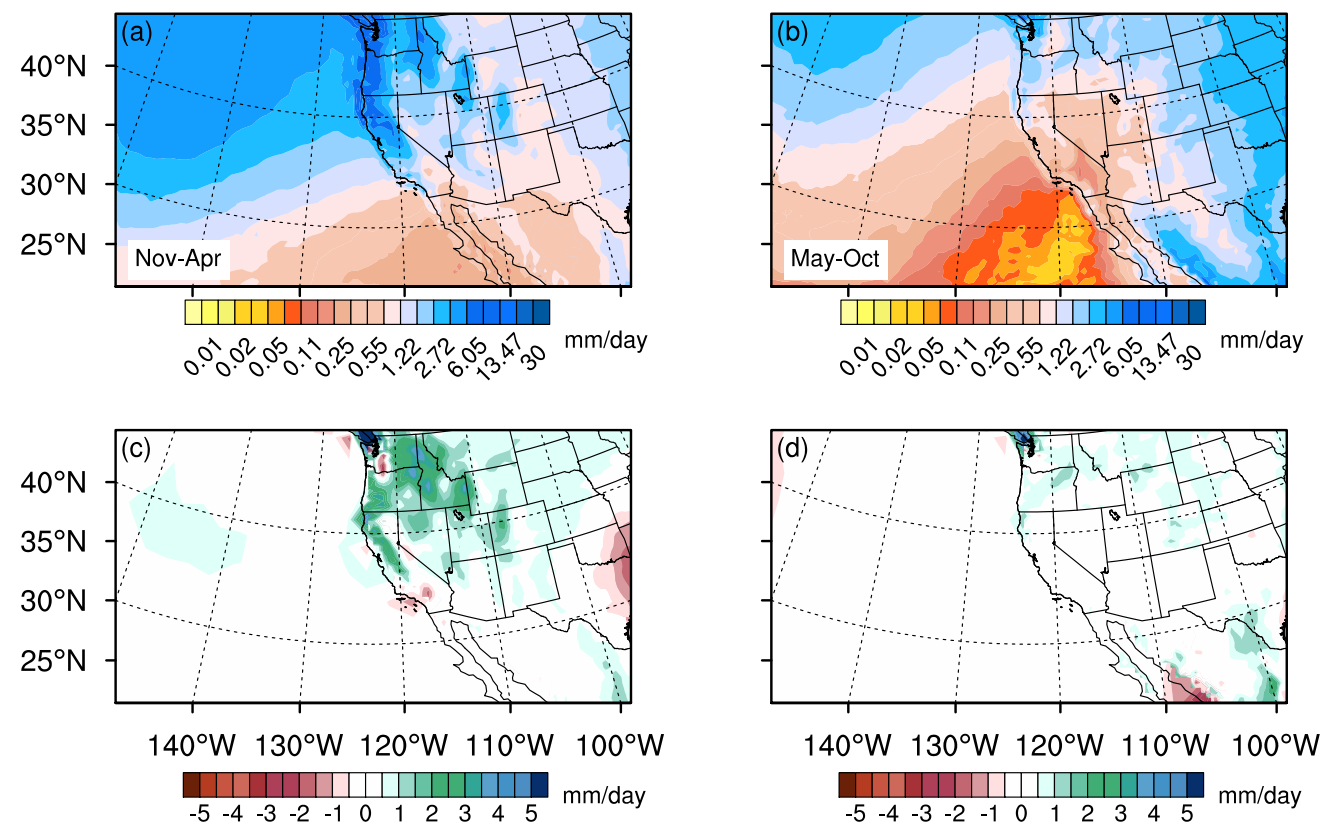

Fig. 4. Precipitation climatology in RegCM-UW (top row), and its difference relative to the CRU (land) and GPCP (ocean) datasets (bottom row). The left column shows the wet season average (November-April), and the right column shows the dry season average (May-October): (a) modeled wet season average precipitation rate, (b) modeled dry season average precipitation rate, (c) RegCM-UW wet season precipitation bias (MODEL-OBS), and (d) RegCM-UW dry season precipitation bias (MODEL-OBS). The color bars for the upper panels are logarithmic to the spatial structure of both high and low precipitation areas. The color bars for the lower panels are linear, and differences less than $1 \mathrm{~mm} \mathrm{day}^{-1}$ are shown as white.

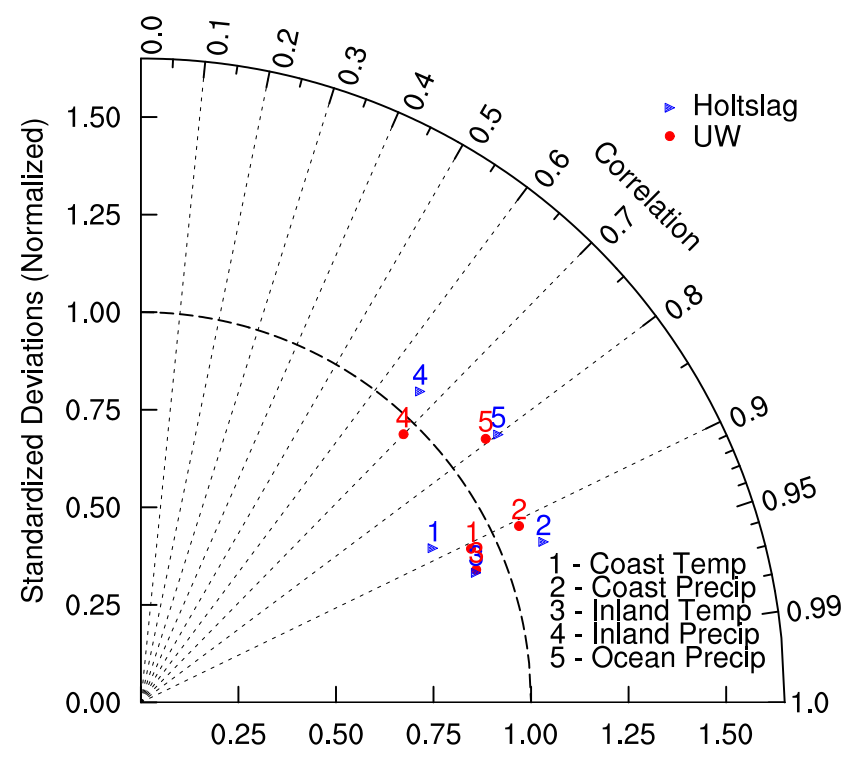

Fig. 5. A Taylor diagram showing the performance of RegCM vs. CRU for the UW and Holtslag models on the WNA domain. The analysis is divided between temperature and precipitation and between coastal grid cells and inland grid cells.
Figure 5 shows that the interannual variability of the UW run matches better with CRU (the red points are closer to the dashed arc in the middle of the diagram) for both coastal and inland precipitation (points 3 and 4), as well as coastal temperature (point 1). Of all the changes in interannual variability associated with adding the UW model, improvement of coastal temperatures and of inland precipitation are the most notable. We attribute the improvement of coastal temperature directly to the improved representation of the marine boundary layer (which we demonstrate in the next section). It is less clear why the UW model improves inland precipitation. Comparison of the UW and HOLT runs indicates that convective precipitation in the UW run is significantly less, in terms of magnitude and variability, than in the HOLT run. We attribute this reduction in convective activity in the UW run to a reduction in the near-surface temperatures (typically about $1 \mathrm{~K}$ ), which should directly reduce the amount of convectively available potential energy, since the level of free convection should be higher on average.

The UW model also slightly improves the interannual correlation of inland precipitation (the angle of the line connecting the origin and point 4 is lower for the UW run than the Holtslag run), and it slightly does the same for coastal temperatures. The UW run slightly worsens the interannual correlation for coastal precipitation (point 2), and it does nothing to change either the variability or correlation of inland 


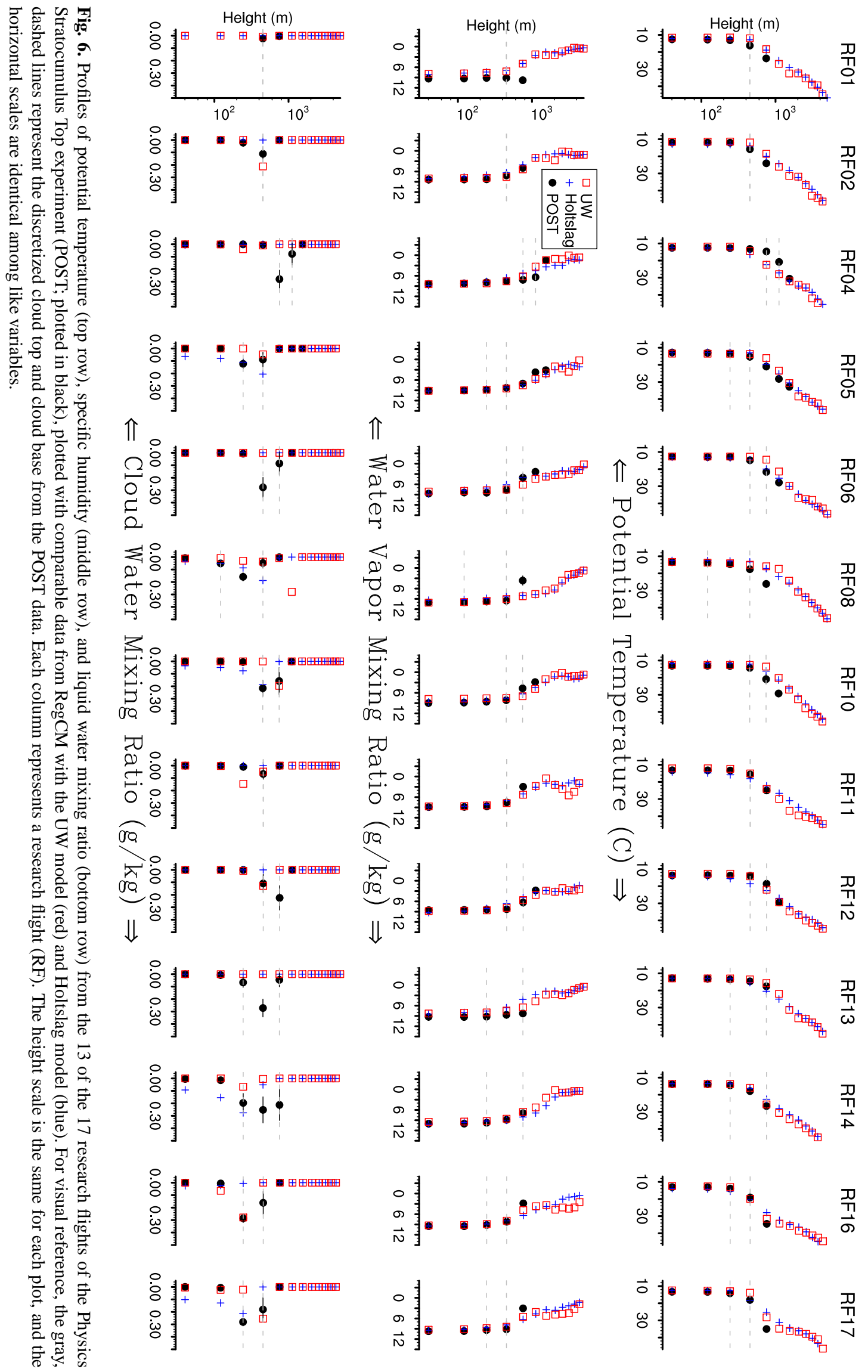


temperature (point 3 ). The UW run slightly improves the interannual variability of oceanic precipitation compared to the Holtslag model, though it slightly worsens the actual correlation between the model output and the observations (GPCP). The correlation between the model runs (both UW and Holtslag) and CRU is generally quite high; the correlation coefficient is between 0.9 and 0.95 for temperature and for coastal precipitation, it is nearly 0.8 for oceanic precipitation, and it is about 0.7 for inland precipitation. Generally, in terms of gross climatology, the UW run reduces the magnitude of the model's interannual variability to a more realistic level.

\section{Comparison with field experiments}

To show that the UW TCM produces MSc in a physically realistic manner, we compare simulated vertical profiles of potential temperature, water vapor mixing ratio, and in-cloud liquid water mixing ratio with data obtained from three field experiments: the second Dynamics and Chemistry of Marine Stratocumulus experiment (DYCOMS II) (Stevens et al., 2003), the Physics of Stratocumulus Top (POST) experiment, and the VAMOS Ocean-Cloud-Atmosphere-Land Study Regional Experiment (VOCALS) (Rahn and Garreaud, 2010a,b).

For all three field experiments, only data collected in the target region of each research flight are utilized; the in-bound and out-bound portions of the trips are discarded. The RCM output are averaged in time over the course of the each research flight (output was saved every model hour for each of the field experiment time periods) and bilinearly interpolated horizontally to the average latitude and longitude of the flight. Instead of vertically interpolating the RCM output, the field experiment data are averaged in vertical bins. The boundaries of the vertical bins are chosen such that they correspond to the geopotential heights of the edges of the RCM's model levels.

\subsection{Flight-by-flight comparison with POST}

Comparison of the model output with in situ data from the POST experiment shows that the UW model generally improves the vertical structure of the boundary layer in RegCM. The POST field experiment was conducted in July and August 2008 and consisted of 17 research flights between 16 July and 15 August, though we use a subset of 13 of these research flights for clarity in Fig. 6 (the 13 flights were chosen at random). The flights took place in both the afternoon and evening off the coast near Monterey, California. The locations of the 13 research flights used in this study are shown as red squares in Fig. 1. The research flights were conducted in a lagrangian fashion, so that the plane approximately sampled the same air mass throughout the flight. The airplane mainly porpoised in and out of the cloud layer to maximize data coverage in the entrainment interface layer, but it periodically surveyed the entire depth of the BL.

Figure 6 shows a set of three vertical profiles from each POST research flight. The in situ data are plotted as black circles, with the UW and Holtslag simulations of each field experiment shown as red squares and blue crosses, respectively. Each research flight has a profile of potential temperature $(\theta)$, water vapor mixing ratio $\left(r_{\mathrm{v}}\right)$, and liquid water mixing ratio $\left(r_{1}\right)$. For compactness, the height scale for the vertical profiles, which is logarithmic to emphasize the boundary layer, is only shown in the first column. These three figures are formatted in this way to show the general success of RegCM at modeling the vertical structure of the atmosphere, and to illustrate differences in the boundary layer structure between the Holtslag and UW runs.

It is striking in Fig. 6 that the modeled boundary layer and free tropospheric profiles of $\theta, r_{\mathrm{v}}$, and $r_{1}$ show a high degree of similarity to the profiles measured during POST. The POST data, as well as both model runs, show a very wellmixed boundary layer capped by a stable, dry, free troposphere. The Holtslag and UW model runs hardly differ from each other, yet the small amount that they do differ makes the difference between whether or not the model exhibits MSc.

Close examination of the water vapor profiles shows that even on days where the boundary layer heights agree between the Holtslag and UW runs (e.g. RF's 02 and 03), the Holtslag model is slightly drier near the top of the boundary layer. Given that the boundary layer water vapor mixing ratios are nearly identical for the UW and Holtslag runs, they should have the same lifting condensation level (LCL), which clearly occurs below the boundary layer top in the UW run. Despite having the same LCL, the slight dryness near the top of the boundary layer precludes the Holtslag run from reaching saturation, which results from the Holtslag model failing to maintain a well-mixed boundary layer all the way up to the top. This failure is likely due to the specification of vertical diffusivities in the Holtslag model, which are constrained to approach zero at the top of the boundary layer (Holtslag and Boville, 1993). In contrast, the UW model produces turbulence from the tops of cloud layers, which allows the diffusivity to remain relatively high under cloudy conditions even at the top of the boundary layer. This cloud-top production of turbulence allows for a feedback, which was originally identified by Lilly (1968), that causes the boundary layer to remain well-mixed (and maintain a supply of moisture to BL clouds despite the drying effects of entrainment) even near the top of the boundary layer.

The UW model generally improves the representation of MSc over the Holtslag model: on RFs 02, 11, and 12 the UW model correctly predicts MSc when the Holtslag predicts none, yet there are no days where the reverse occurs. There are 2 days where the UW model predicts no MSc when it should (RFs 04 and 13), and one day where the modeled $\mathrm{MSc}$ is present but dramatically too thin (RF 06). Furthermore, on most of the days that the Holtslag model predicts 
low cloud, it has an unrealistically low cloud base (RFs 05, $10,14,17)$. While the UW model is somewhat sporadic in its placement of the top of the cloud (the inversion height), it produces a realistically high cloud base. On average, cloud base for the Holtslag model occurs at approximately $80 \mathrm{~m}$, whereas it averages $370 \mathrm{~m}$ for both the UW model and the POST data.

The BL top temperature inversion, measured by the jump in potential temperature above the boundary layer top ${ }^{6}$, is stronger on average in the UW runs $(7.0 \mathrm{~K})$ than the Holtslag runs $(5.5 \mathrm{~K})$, which is closer to the average strength from the flight profiles $(9.9 \mathrm{~K})$. The thorough mixing at the top of the boundary layer due to cloud-top radiative cooling, which the Holtslag model lacks, is responsible for developing the strong temperature inversions seen in both the POST data and the UW run.

The height of the inversion appears to vary too much for the UW model (e.g. RFs 04, 08, 11), but on average the inversion height is higher in the UW run than the Holtslag run, putting it closer to the observed inversion height. The inversion height averages $450 \mathrm{~m}, 540 \mathrm{~m}$, and $620 \mathrm{~m}$ for Holtslag, UW, and POST, respectively. Overall, the clouds in the UW model are either too thin or do not have high enough liquid water mixing ratios, leading to a low bias in integrated liquid water content (liquid water path; LWP). LWP in the Holtslag run averages $36 \mathrm{~g} \mathrm{~m}^{-2}$, the UW run does slightly worse at $31 \mathrm{~g} \mathrm{~m}^{-2}$, while the POST data average $80 \mathrm{~g} \mathrm{~m}^{-2}$. The Holtslag model's LWP are higher on average because the modeled BL clouds span from the surface to the BL top on the four of the five days (RFs 08, 10, 14, and 17) where the Holtslag model simulates BL clouds.

Considering that these runs have ample time (i.e. more than 20 model years) to develop mesoscale circulations that are not influenced by initial conditions, and that may differ considerably from the circulations in the coarser boundary condition data (von Storch et al., 2000), it is remarkable that the thermodynamic profiles match the POST data as closely as they do. Such successful modeling of the vertical structure of the lower troposphere, after $25 \mathrm{yr}$ of model simulation, attests to the potential for regional climate models to successfully dynamically downscale reanalysis data.

\subsection{Comparisons with DYCOMS II and VOCALS}

In this section, we briefly describe the DYCOMS II and VOCALS missions, and the model runs used to compare with them. Most of the salient details of these comparisons are similar to that from POST, so the discussion here is much shorter. Data from these comparisons are synthesized in Sect. 6.3; the main purpose of this section is to provide background for these runs and to show data from the flight profiles that are presented in a condensed form in Sect. 6.3.

\footnotetext{
${ }^{6}$ Note that these jumps occur on the finite model grid, whose spacing varies between about $125 \mathrm{~m}$ and $175 \mathrm{~m}$ for the the range of boundary layer depths shown.
}

DYCOMS II was composed of a series of 10 research flights several hundred kilometers off the coast of Southern California during the month of July 2001, during the peak of the MSc season. The locations of the research flights (RF) used in this study are shown as green circles in Fig. 1. The flights were done primarily at night to avoid the complication of solar heating in the boundary layer energy budget. To compare with the DYCOMS II data, we use model output from the WNA-UW-SHORT and WNA-HOLT-SHORT runs, which are described in Sect. 4.1. These runs are shortened, one-month versions of the longer WNA experiments (WNAUW-LONG and WNA-HOLT-LONG) but with higher vertical resolution: 30 model levels instead of 23 (the additional levels are concentrated below approximately $1 \mathrm{~km})$. We initially compared output from WNA-UW-LONG, but we were surprised to find that UW model did not simulate MSc in the DYCOMS II area during most of the research flights. A sensitivity test indicated that the model's vertical resolution has a significant impact on the simulation of boundary layer profiles. With 30 vertical levels, which is shown in the comparison in Fig. 7, the UW model produces MSc during all of the research flights. This performance in simulating stratocumulus occurrence is notably better than from the lower-resolution (and longer integration) WNA-UW-LONG in comparison with POST data; this is likely due to the increased vertical resolution, though this should be a topic of future study. Despite the increased vertical resolution, the modeled liquid water path is systematically too low: the experiment-average LWP calculated on this vertical grid is $45 \mathrm{~g} \mathrm{~m}^{-2}$ for the UW model in contrast to $124 \mathrm{~g} \mathrm{~m}^{-2}$ from the flight profiles.

The VAMOS Ocean-Cloud-Atmosphere-Land Study Regional Experiment (VOCALS) is a field experiment that took place off the coast of South America between 15 October 2008 and 15 November 2008. A wide variety of platforms and instruments were involved in the collection of data during the VOCALS campaign, as described by Rahn and Garreaud (2010a), but this section focuses specifically on data collected by the CIRPAS Twin Otter. On the 14 flights of the Twin Otter, the flights took off consistently at about 11:00 Z (08:00 LT) and landed by about 16:00 Z (about 13:00 LT), with the exception of RFs 01 and 08, which started and ended about three hours later than the other research flights. A main goal of the Twin Otter mission was to consistently sample the same approximate location (approximately $23^{\circ} \mathrm{S}, 72^{\circ} \mathrm{W}$ ) at the same time of day for the duration of the mission. The domain utilized in this study is shown in Fig. 2, and is described in detail in Sect. 4.2. Figure 8 shows data from the VOCALS flights and the VOCALS-UW and VOCALS-HOLT runs.

Unlike DYCOMS II and POST, the UW and Holtslag runs differ substantially in the vicinity of the boundary layer top. This difference appears to be due to a combination of the Holtslag model failing to develop a deep enough boundary layer and failing to develop a strong enough inversion on most days. In general, the boundary layer depths in VOCALS 

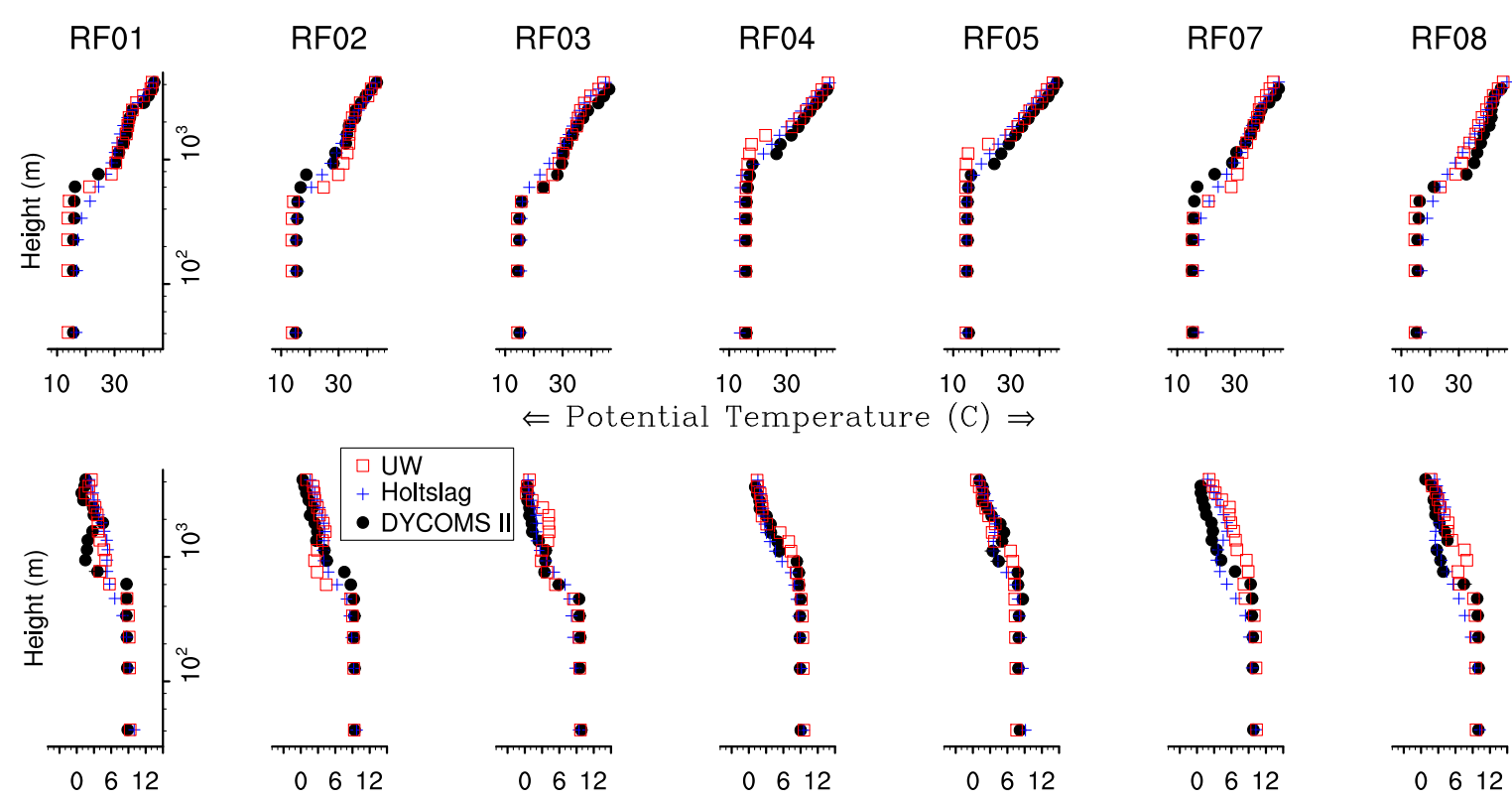

$\Leftarrow$ Water Vapor Mixing Ratio $(\mathrm{g} / \mathrm{kg}) \Rightarrow$
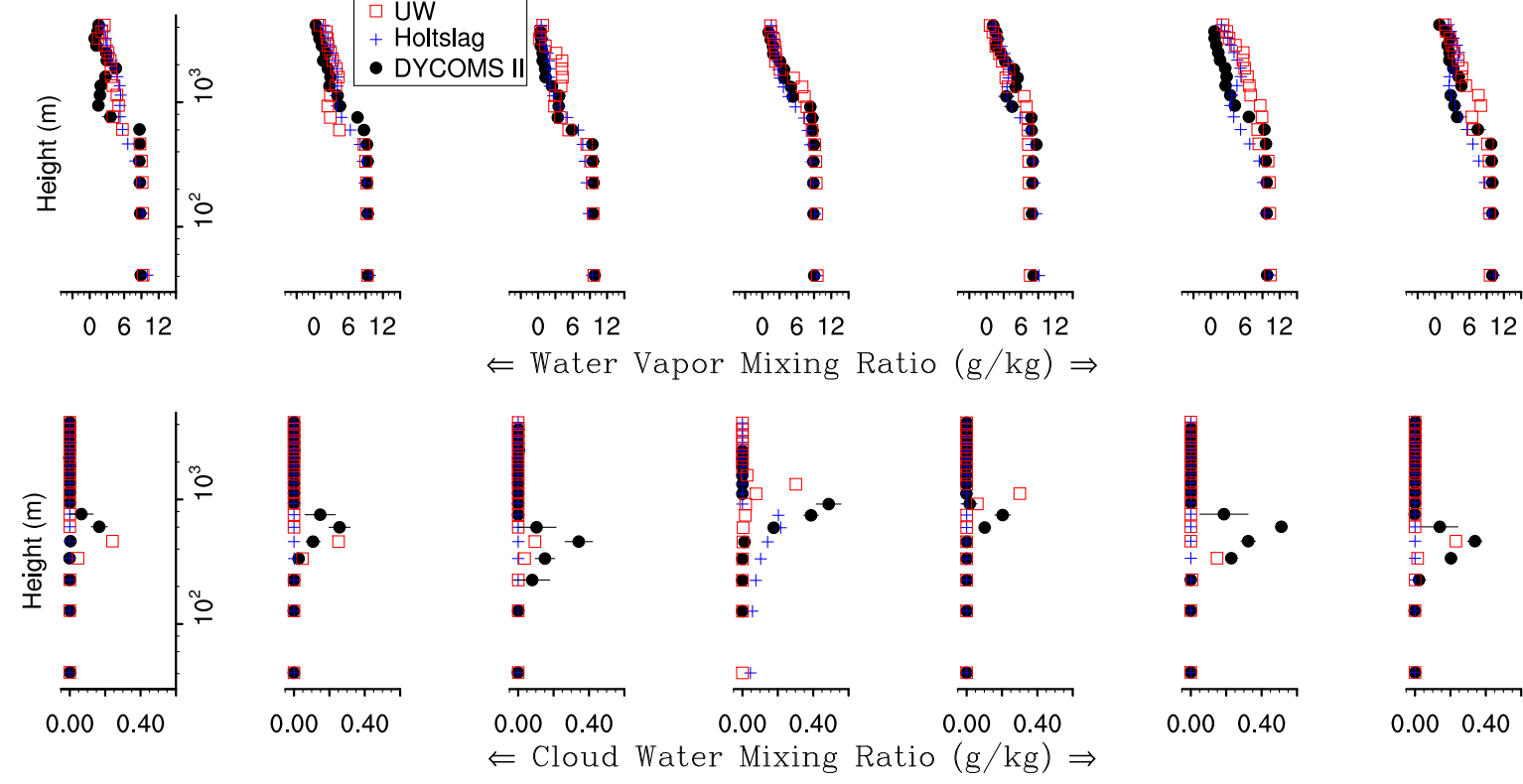

Fig. 7. Profiles of potential temperature (top row), specific humidity (middle row), and liquid water mixing ratio (bottom row) from 7 of the 10 research flights of the second Dynamics and Chemistry of Stratocumulus Experiment (DYCOMS II; plotted in black), plotted with comparable data from RegCM with the UW model (red) and Holtslag model (blue). Each column represents a research flight (RF). The height scale is logarithmic and is the same for each plot, and the horizontal scales are identical among like variables.

are deeper than either DYCOMS II or POST; the BL height is typically $1 \mathrm{~km}$ or greater. While the UW model tends to predict a deeper boundary layer than the Holtslag model, it still tends to be too shallow relative to the observed boundary layer. Despite this low boundary layer bias, the UW model places the BL top above the lifting condensation level on all but two days (RFs 03 and 13). In contrast, the Holtslag model only predicts low cloud on one of the 13 days (RF03), and as with DYCOMS II and POST, the cloud base from the Holtslag run is unrealistically low. As shown in DYCOMS II and POST, the UW model seems to have a systematic low bias in liquid water path: it is $31 \mathrm{~g} \mathrm{~m}^{-2}$ on average for the UW run compared to $53 \mathrm{~g} \mathrm{~m}^{-2}$ from the flight profiles.

\subsection{Field experiment summary}

All three field experiments, which represent a range of MSc conditions (daytime, nighttime, nearshore, offshore, deep, shallow), tell a common story about the general success of
RegCM at representing the vertical structure of the atmosphere over the ocean: (1) RegCM forced by NCEP II reanalysis has a surprisingly good representation of the lower troposphere, (2) the addition of the UW model substantially improves that representation by adding MSc (and associated processes) to the model, and (3) RegCM with the UW model systematically under-predicts the integrated water content of MSc. Stevens et al. (2005) indicate that large-eddy simulations suffer from a similar problem due to excessive entrainment; entrainment may also be the culprit here. It is possible that tuning the evaporative feedback parameter in the UW model (which is poorly constrained) could help this bias. A future study should examine the impact of this parameter in $\mathrm{RegCM}$ to see whether a value can be chosen that improves the LWP. Such a study will have to take care that retuning this parameter does not degrade the overall representation of the boundary layer (Grenier and Bretherton, 2001). It may also be worth investigating whether other entrainment parametrizations can improve the LWP bias. It is also 


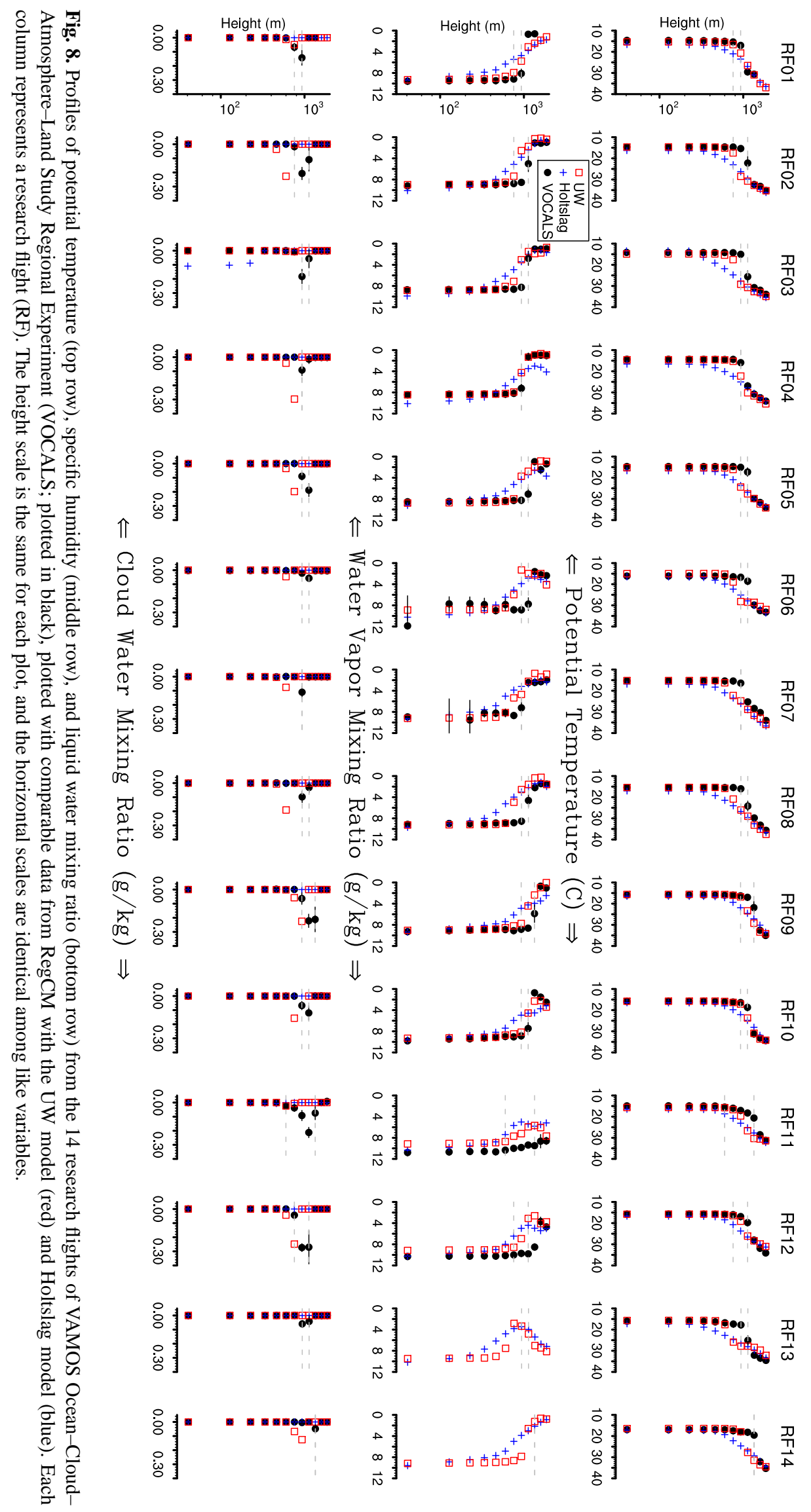




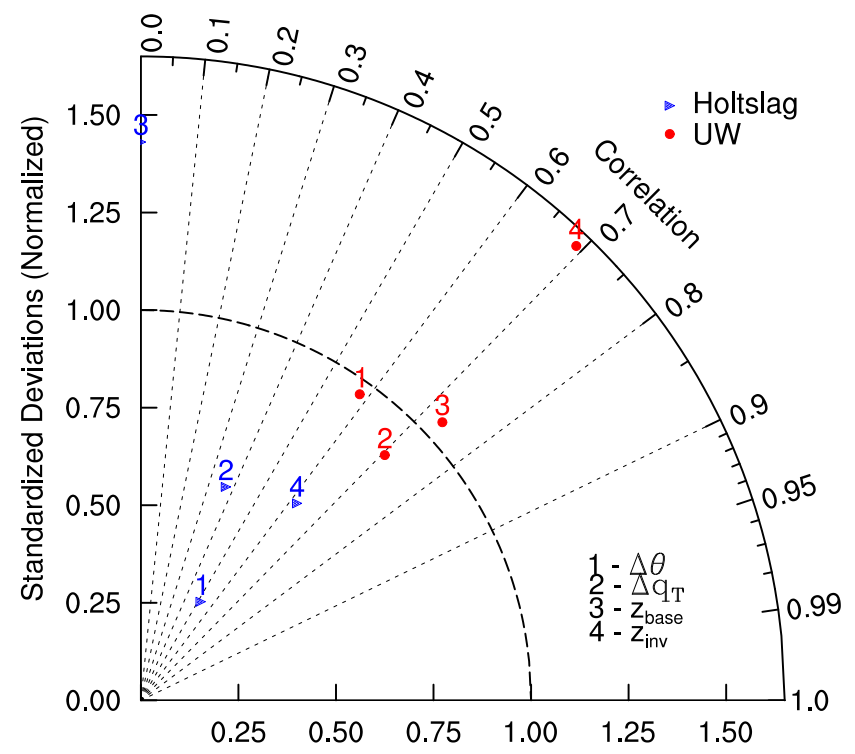

Fig. 9. A Taylor diagram comparing the representation of day-today variations in boundary layer properties in the UW and Holtslag model runs (red-filled circles and blue triangles, respectively) against DYCOMS II, POST, and VOCALS in situ data. Correlations and ratios of standard deviations are depicted for the following variables: boundary layer inversion strength $(\Delta \theta)$, jump in water vapor mixing ratio at cloud top $\left(\Delta q_{\mathrm{T}}\right)$, cloud base height ( $\left.z_{\text {base }}\right)$, and inversion height $\left(z_{\text {inv }}\right)$.

possible that systematically excessive precipitation (drizzle) may cause the the low LWP bias. Figure 4 indicates that precipitation rates over the ocean are within the range of observations, however this does not rule out the possibility that precipitation rates are too low for low-LWP clouds and too high for high-LWP clouds. If this were the case, then the mean precipitation rate might be correct, but precipitation would act as an excessive moisture sink when LWP begins to become large, thus limiting the growth of LWP. A future study might investigate this by comparing LWP-sorted drizzle rates between model and observations.

In addition to the average improvements in the representation of the boundary layer by the UW model, the UW model also improves the representation of the time-evolution of the boundary layer. Figure 9 shows a Taylor diagram of the boundary layer inversion strength $(\Delta \theta)$, the decrease in water vapor mixing ratio at cloud top $\left(\Delta q_{\mathrm{T}}\right)$, the cloud base height $\left(z_{\text {base }}\right)$, and the inversion height $\left(z_{\text {inv }}\right)$. The correlations and standard deviations were calculated individually for each variable, within each field experiment, and then averaged (root mean square average) to produce the correlations and standard deviations shown in Fig. 9. Calculated in this way, the standard deviations and correlations represent average intra-experiment values.

Figure 9 shows that the UW model improves the representation of the boundary layer by almost every metric. The standardized deviation of the inversion strength is very nearly 1 for the UW model, whereas it is only slightly larger than 0.25 for the Holtslag run. The correlation coefficient for the UW run is modestly closer to 0.6 than the coefficient for the Holtslag model, which is closer to 0.5 . The UW model definitely improves the representation of the inversion strength relative to the Holtslag model. The inversion-top decrease in water vapor mixing ratio is similarly improved. The variability of $\Delta q_{\mathrm{T}}$ is again closer to 1 for the $\mathrm{UW}$ model, and its correlation coefficient is much higher, with $r \approx 0.7$ for the UW model and $r \approx 0.4$ for the Holtslag model. Interestingly, despite the expected relationship (they should positively correlate) between the boundary layer height and inversion strength (Tennekes, 1973), the variability of the inversion height (which is equivalent to the boundary layer height) is worsened in the UW model. The standardized deviation is about $50 \%$ too high in the UW runs, whereas it is about $50 \%$ too low in the Holtslag runs. The inversion height in the UW runs does correlate slightly better with the flight data than the Holtslag runs (nearly $r \approx 0.7$ versus $r \approx 0.6$ ), but it varies too strongly, as shown by the standardized deviation. Despite a boundary layer height that varies too greatly, the inversion strength varies with almost a perfect magnitude; it seems that there must be feedbacks in the model that constrain the variability of the inversion strength (e.g. the explicit inverse relationship between inversion strength and entrainment rate; Grenier and Bretherton, 2001).

Just from visual inspection of the bottom rows of Figs. 6, 7 , and 8 , it is clear that the UW model dramatically improves the prediction of cloud base relative to the Holtslag model, given that the Holtslag model tends to predict either no cloud, or a cloud with an unrealistically low base (i.e. at the surface). In Fig. 9, this is reflected as essentially no correlation, and too high of a variability in $z_{\text {base }}$ in the Holtslag model. In contrast, cloud base from the UW model varies with a realistic magnitude (the standardized deviation is only slightly too large), and it correlates quite well with the in situ data $(r \approx 0.75)$.

The generally higher correlation between the day-to-day variability of the UW model and the in situ data indicates that the boundary layer properties in the UW model respond to synoptic-scale variability in a more realistic manner than the Holtslag model. As expected, the addition of stratocumulus physics, through the UW model, definitely improves the representation of the boundary layer and boundary layer physical processes in RegCM.

\section{Stratocumulus climatology}

The results from the previous section show that RegCM-UW improves the representation of MSc at short (synoptic) time scales. This section describes and validates the climatology of MSc in RegCM-UW at scales ranging from diurnal to decadal. 
For western North America, the dry season months of May through October closely correspond to the MSc season, with the season typically peaking in July. During this season, the stratocumulus deck strengthens (cloud fraction and liquid water path increase) and the deck approaches the coast. This strengthening of the cloud deck is associated with an increase in lower tropospheric stability (Klein and Hartmann, 1993; Lin et al., 2009) or alternatively an increased inversion strength (Wood and Bretherton, 2006). During the summer, the boundary layer height and cloud-base lower in the vicinity of the coast (e.g. Dorman et al., 2000). The decrease in BL height with decreasing distance from the coast is driven by the nearshore enhancement of subsidence rate associated with a mountain-thermal circulation, and to a lesser extent, cooler sea surface temperatures adjacent to the coast (Burk and Thompson, 1996). Figure 10a and b shows a transect along the $35^{\circ} \mathrm{N}$ parallel ${ }^{7}$ depicting various aspects of the structure of the boundary layer for the wet seasons and dry seasons, respectively, that is in accord with these qualitative observations of the marine boundary layer.

The model's marine BL exhibits a well mixed boundary layer in both seasons, as shown by the essentially constant potential temperature profile (the colored and filled cells), up to the center of the cloud deck (the gray contour lines show contours of constant liquid water mixing ratio). The cloudwater mixing ratios are higher on average during the dry season than during the wet season, with the liquid water mixing ratio reaching as high as about $8-9 \times 10^{-2} \mathrm{~g} \mathrm{~kg}^{-1}$ during the summer and 6-7 $\times 10^{-2} \mathrm{~g} \mathrm{~kg}^{-1}$ during the wet season.

The average boundary layer top, which is approximately depicted by the outer-most cloud-water contour below $700 \mathrm{hPa}$, lowers toward the coast in both the wet and dry seasons, but it does so much more pronouncedly in the summer. The black vectors depict the zonal and vertical wind directions, with the vertical velocity greatly scaled so that its average magnitude is similar to magnitude of zonal wind. There is generally subsidence throughout the stratocumulus deck, with the subsidence rate increasing approaching the coast. The model shows liquid water very near the surface adjacent to the coast, which suggests that the model may have skill in simulating fog. The zonal component of the wind during the dry months gives the wind field a relatively strong on-shore component, which when added to the heightened subsidence near the coast that drives the BL height downward, is likely why the deck approaches the ground near the coast.

\subsection{Condensed water path}

During the summer (JJA) months in the WNA MSc region, which is dominated by subsidence on average and typically is free of storm-systems, the total column burden of condensed water (i.e. condensed water path) represents an integrated

\footnotetext{
${ }^{7} 35^{\circ} \mathrm{N}$ was chosen to be representative of the stratocumulus deck. Transects along other parallels yield similar profiles.
}
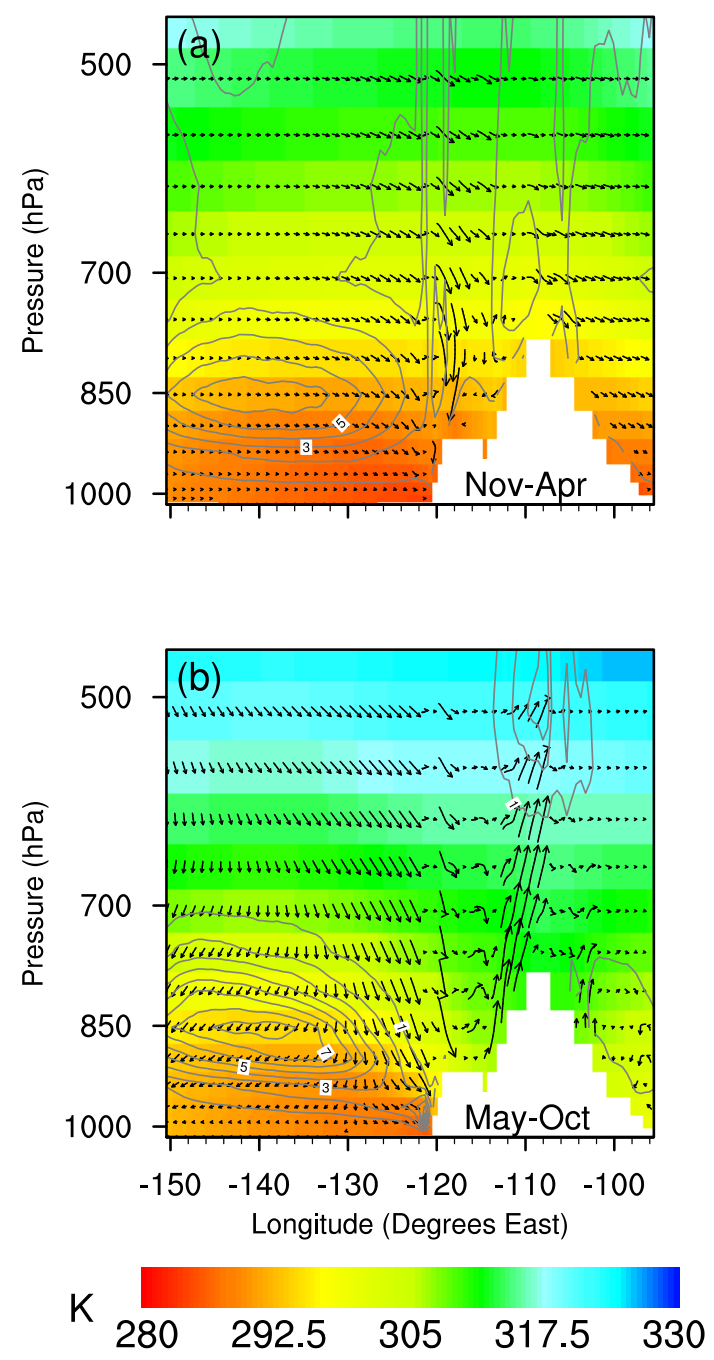

Fig. 10. UW run climatology (December 1984-November 2009) for the wet season (a) November-April) and the dry season (b; MayOctober), along a longitudinal transect on the $35^{\circ} \mathrm{N}$ parallel (shown in Fig. 1). The colors show the potential temperature, the gray contours show the liquid water mixing ratio (in $\mathrm{cg} \mathrm{kg}^{-1}$ ), and the vectors depict the air flow pattern. The vertical velocity is scaled such that its average is equal to the average zonal velocity to emphasize the vertical flow.

measure of boundary layer processes. While we show in Sect. 6 that the UW model's liquid water path (which is nominally equivalent to condensed water path (CWP) for the summertime MSc regime) is comparable to that measured in the DYCOMS II, POST and VOCALS experiments (but biased low), these comparisons are limited to specific locations and times. By comparing modeled CWP with CWP from satellite data, shown in Fig. 11, we show that the UW model distinctly improves the representation of boundary layer processes across the entire WNA MSc region. This comparison gives a spatial and a climatological context to the validation of MSc simulation in RegCM. 

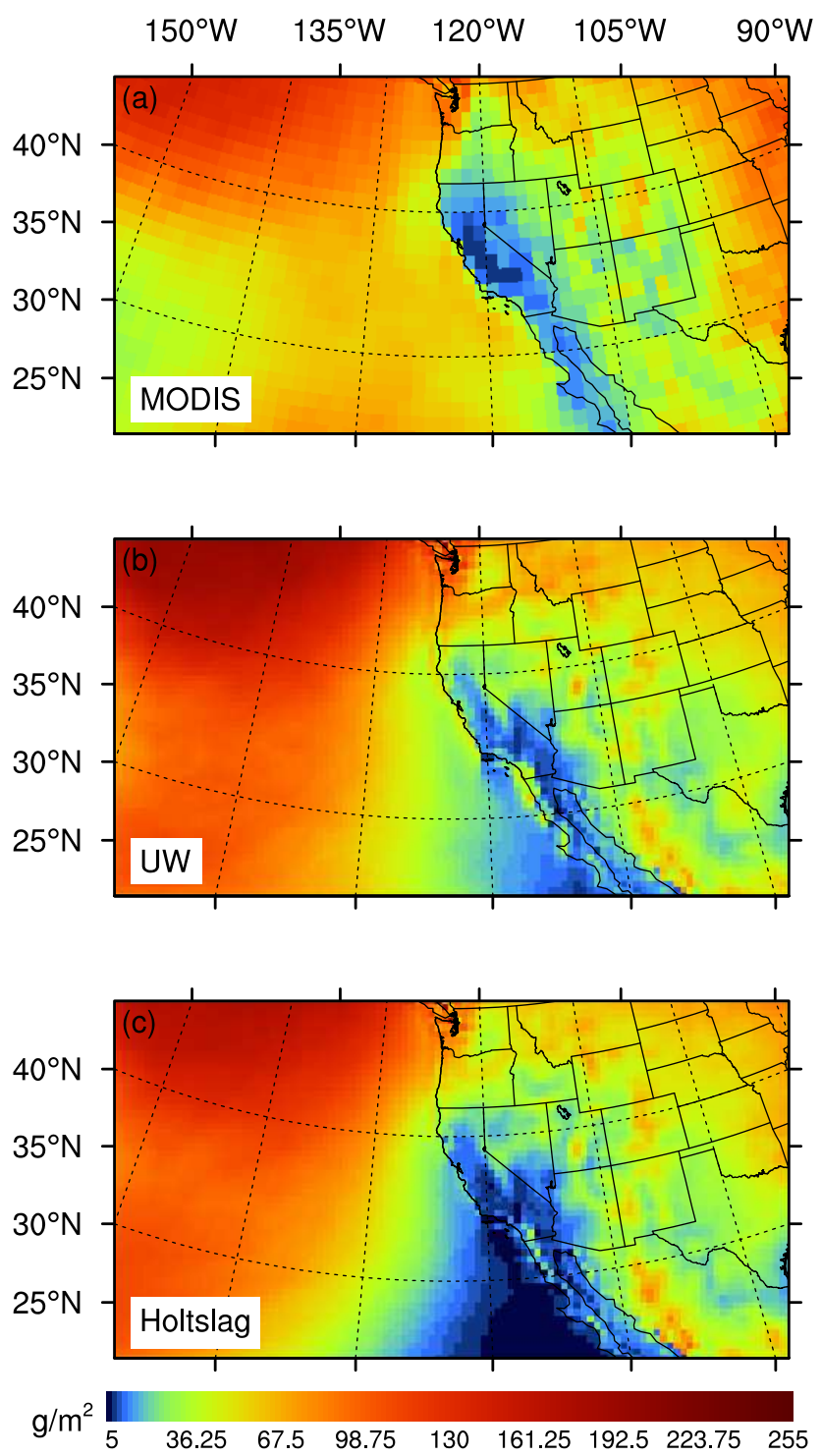

Fig. 11. Condensed water path (liquid and ice combined; $\mathrm{g} \mathrm{m}^{-2}$ ) for JJA 2001-2009: (a) from MODIS (b) RegCM4.1 with UW TCM, (c) RegCM4.1 with Holtslag BL.

Vertical integration of in-cloud condensed water path requires an assumption about the nature of horizontal overlap of cloud layers. In the limit of non-overlapping clouds, CWP is calculated as the vertical average of condensed water content, whereas in the limit of perfectly overlapping clouds, CWP is calculated as the vertical sum instead. The radiation parametrization in RegCM uses a random overlap assumption (Briegleb, 1992), which could be used to vertically integrate condensed water content. However, with that method, CWP would be strongly controlled by this assumption, which complicates the use of CWP as a metric for boundary layer processes. To avoid this complication, we instead use gridcell average condensed water path, which can simply be calculated as the vertical sum of cell-average condensed water content; cell-average CWP requires no assumption about the overlap of cloud layers.

For the satellite data, we used monthly mean cloud product from the MODIS Terra platform (the MOD08_M3 product), which spans the years 2000-2010 (Hubanks et al., 2008), though we only use data from 2001-2009. We omit 2000 because of artifacts in the data at the beginning of the year, and we omit 2010 because the RegCM run only goes through 2009. We use an approximate cell-average CWP, which we calculate by multiplying CWP by the average cloud fraction for each cell ${ }^{8}$.

Figure 11 shows the JJA average CWP from 2001-2009 for the WNA domain (the model output comes from the WNA-UW-LONG and WNA-HOLT-LONG experiments). The MODIS data and the RegCM-UW output show a relatively high degree of spatial similarity overall, with a correlation coefficient of $r=0.71$. With both the UW model and the Holtslag model, RegCM places the northeastern Pacific cloud deck in the correct location, though it is slightly too strong. The MSc deck in the southern portion of the domain is also slightly too strong, and it is shifted approximately $10^{\circ}$ to the west relative to MODIS (see the southern portion of the domain in Fig. 11a and b; the center of the UW deck occurs at approximately $30^{\circ} \mathrm{N}, 140^{\circ} \mathrm{W}$, whereas the MODIS deck is centered closer to $25^{\circ} \mathrm{N}, 130^{\circ} \mathrm{W}$ ).

Unlike with the Holtslag model, the UW model has a stratocumulus deck adjacent to the coast (Sect. 6 shows that the CWP in the near-coastal region is indeed stratiform). Despite having a stratocumulus deck with the UW model, however, the deck's CWP tends to be too low relative to MODIS, especially at the southern portion of the coast. The CWP from the UW model is $30-40 \mathrm{~g} \mathrm{~m}^{-2}$ too low on average in this region, while it is $50-60 \mathrm{~g} \mathrm{~m}^{-2}$ too high over the western and northern portions of the ocean. This low CWP bias is consistent with the low LWP biases noted in comparing RegCM against the three field experiments in Sect. 6. As mentioned in Sect. 6, we noted that at higher vertical resolution the model is more consistent at (correctly) producing MSc. The data shown in Fig. 11 come from a run with only 23 vertical levels, so it is possible that this low CWP bias may be fixed with a higher vertical resolution run. This possibility should be explored in a future study.

\subsection{Time evolution}

The previous sections show that the UW model improves the vertical and horizontal representation of MSc relative to the Holtslag model, but they give no indication of the time evolution of MSc in the UW model. To show the time evolution of low cloud coverage (including MSc) at multiple temporal scales, we compare the modeled low cloud amount from

\footnotetext{
${ }^{8}$ For CWP and cloud fraction, we used the variables "Cloud Water Path Combined Mean Mean" and "Cloud Fraction Combined Mean FMean", respectively.
} 


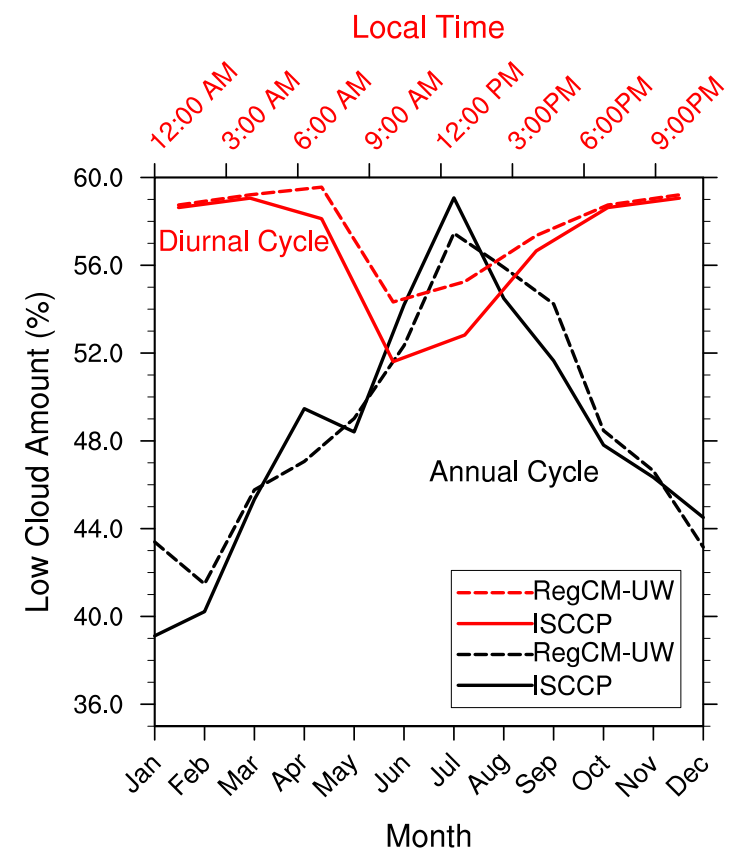

Fig. 12. The annual and diurnal cycles of low cloud coverage, averaged from 1985 to 2006 . The solid curves show ISCCP satellite measurements of low cloud amount, and the dashed curves show the modeled RegCM-UW low cloud amount shifted downward by $25 \%$ for clarity (meaning RegCM-UW is biased approximately $25 \%$ too high). The solid curves depict the average annual cycle and the red curves depict the average JJA diurnal cycle.

RegCM-UW to satellite data from the International Satellite Cloud Climatology Project (ISCCP: Schiffer and Rossow, 1983; Rossow and Schiffer, 1999). ISCCP uses radiances measured from multiple geostationary satellites to infer information about the state of the atmosphere, and has been operational since 1983. In Figs. 12 and 13, we use the low cloud amount ${ }^{9}$ from the D2 data set, which consists of diurnal averages for each month of operation, gridded on a $2.5^{\circ}$ grid. For direct comparison of the ISCCP data against the WNA-UWLONG experiment, we show $20 \mathrm{yr}$ of data and model output from January 1985 to December 2006.

Figure 12 shows both the JJA-average diurnal cycle and the annual cycle of low cloud coverage, spatially averaged within the dashed box region shown in Fig. 1 (this area is chosen to be representative of the stratocumulus deck). We note here that the RegCM-UW low cloud amount is shifted downward by $25 \%$ in Fig. 12 because the RegCM-UW cloud fraction is biased approximately $25 \%$ too high. Changing the cloud fraction threshold in the RegCM cloud parametrization likely could ameliorate this high cloud-coverage bias (Pal et al., 2000). However, this high bias also may indicate that the cloud fraction parametrization in RegCM is too simplistic and not based strongly enough on physical processes.

\footnotetext{
${ }^{9}$ Defined as the fractional coverage of clouds occurring below $680 \mathrm{hPa}$.
}

A future study should examine utilizing turbulent moments from the UW model to estimate sub-grid scale moisture variability and fractional cloudiness, as is done by Grenier and Bretherton (2001).

Despite the cloud-coverage bias, RegCM does an excellent job of modeling the phase and amplitude of the annual cycle, as shown by the black curves in Fig. 12. As in the ISCCP data, modeled low cloud coverage is maximal in the JJA months, with a peak in July, and minimal in the DJF months. RegCM-UW also captures the MAM onset and SON decay of the deck; the modeled slopes (rate of change of cloud fraction) during these transition months are comparable to those from ISCCP. The successful modeling of the annual cycle shows that the MSc field in RegCM responds realistically to changes in large scale climatological forcing.

RegCM-UW also responds realistically to diurnal forcing; the JJA diurnal cycles of low cloud cover are very similar between RegCM-UW and ISCCP, as shown by the red curves in Fig. 12. ISCCP shows the well-know nightly maximum in cloud coverage (approximately 21:00 to 06:00 LT), which is followed by a daytime "burn off" (a decoupling of the deck from its surface source of moisture, caused by incloud solar heating; Bretherton and Wyant, 1997). RegCMUW also shows these features, although the modeled daytime "burn off" is somewhat weaker. That RegCM-UW successfully models the diurnal cycle of low cloud amount suggests that the model is representing the decoupling processes (Bretherton and Wyant, 1997) in a realistic way. However, the dampened diurnal cycle might indicate that the decoupling process is either not strong enough, or does not happen frequently enough. As shown by Bretherton et al. (2004a), the addition of a shallow cumulus parametrization to $\mathrm{RegCM}$ may help improve the representation of the decoupling process.

Figure 13 shows the interannual variability of JJA-average low cloud amount between 1985 and 2006, from ISCCP (black, solid) and RegCM-UW (red, dashed). While RegCMUW does not appear to exhibit as much interannual variability as the ISCCP data, RegCM does generally capture the high- and low-cloud amount years; ISCCP and RegCM have a statistically significant $(P>99.9 \%)$ correlation of $r=0.67$. It is notable that the ISCCP data show a general decline in low cloud amount over this time period, with much of the decline occurring after the year 2000. On average, the ISCCP low cloud amount declines at an average rate of $-3 \pm 1 \%$ decade $^{-1}$. The modeled low cloud amount also declines over this period, although at a much slower (statistically insignificant) rate: $-0.5 \pm 0.8 \% \mathrm{decade}^{-1}$ for RegCMUW. Evan et al. (2007) show that trends in the ISCCP data may be partly (artificially) caused by a drift in the satellite viewing angle. Therefore, while the trend in RegCMUW differs from the ISCCP trend in a statistically significant manner, the difference in trends should be treated with caution since the ISCCP trend may not totally represent a change in the cloud deck. 


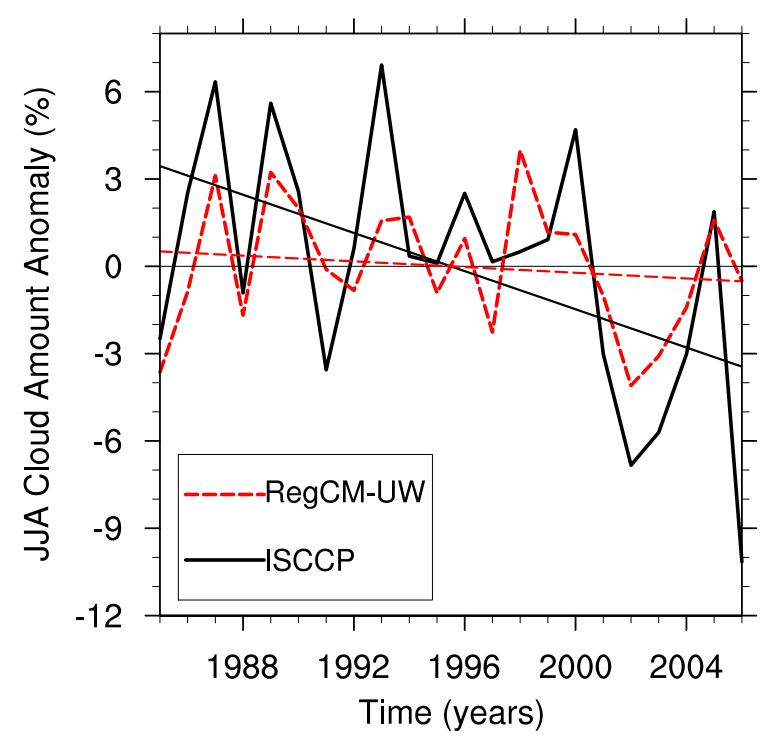

Fig. 13. Interannual variations in JJA-average low cloud fraction anomaly (the mean is removed, and the variability is preserved). The solid, black curve shows data from ISCCP; and the dashed, red curve shows output from RegCM-UW. Regression lines are also drawn through both curves: ISCCP declines at a rate of $-3 \pm 1 \%$ decade $^{-1}$, and RegCM-UW declines at a rate of $-0.5 \pm 0.8 \%$ decade $^{-1}$. The correlation between the two timeseries is $r=0.67$, which is statistically significant above the $99.9 \%$ confidence level.

Norris and Leovy (1994), Norris (2000), and Clement et al. (2009) use ship- and satellite-based observations to show that the long-term variability (interannual and longer) of low clouds in the Pacific is related to variability in SSTs and possibly to variability in the position of the mid-latitude storm track. Though the trend is not statistically significant, the sign of the modeled trend in low cloud amount is consistent with the results from Clement et al. (2009), which show that low cloud amount in this region declined steadily over the last half of the century. This result hints that RegCM-UW exhibits the positive low-cloud climatological feedback shown by Clement et al. (2009). The modest success of RegCM-UW in simulating the long-term variability of MSc cloud amount suggests that it captures these relationships, though the exact mechanism through which SSTs and other climatological forcing affect long-term MSc variability in RegCM-UW is unclear. A future study that examines the causal relationships between MSc and climatological forcing can hopefully reveal the nature of long-term MSc variability in the real world.

\section{Discussion and summary}

This study shows that RegCM-UW models a realistic climatology for western North America, as compared to CRU, GPCP, and SCOW. RegCM-UW tends to have temperatures that are slightly too cold and it has a high precipitation bias, though the model biases are within an acceptable range. Furthermore, we suspect that refinement of the land surface albedos, following (O'Brien et al., 2012) will help fix part of the cold bias. The UW model also improves the interannual variability of temperature and precipitation in RegCM, compared with the Holtslag model.

This study also shows that RegCM-UW simulates a realistic stratocumulus deck at a range of spatial and temporal scales. The comparison with aircraft in situ data (DYCOMS II, POST, and VOCALS) shows that the UW model improves the vertical representation of the lower troposphere relative to the Holtslag model. While the UW model generally predicts an MSc layer comparable to the layers shown in the field data, the comparisons show that RegCM-UW systematically predicts a MSc layer that is too low and that has too little liquid water. The comparison of JJA-average condensed water path from RegCM-UW and MODIS shows a similar story; clouds in the near-coast environment RegCM-UW tend to have too little condensed (liquid) water. Wyant et al. (2010) show that CAM with the UW model also simulates stratocumulus with systematically low LWP, so this LWP bias may be associated with some aspect of the UW model (e.g. the entrainment parameterization), with the relatively low vertical resolution, or some combination of these factors. A future investigation should examine the sensitivity of RegCM-UW to horizontal resolution, vertical resolution, and to tunable model parameters to see if this low-CWP bias can be reduced without degrading the simulation of MSc elsewhere.

The general success of RegCM-UW in the field experiment comparison shows that RegCM-UW represents MSc reasonably well, even at the model's smallest scales (30$50 \mathrm{~km}$ ), and it represents MSc distinctly better than the Holtslag model. The comparison of RegCM-UW output with data from MODIS shows that RegCM-UW also reasonably represents the MSc at the mesoscale; RegCM-UW models a cloud deck that generally conforms to the coastline as in the MODIS data. This comparison also shows that RegCM-UW has a low bias in CWP in the near coastal region, and the MSc deck is shifted nearly $10^{\circ}$ to the west of the deck in MODIS data. It is possible that higher vertical resolution and the addition of a shallow cumulus model to RegCM-UW may fix the low CWP bias and the westward displacement of the MSc deck.

Intercomparison of the field experiments, shown in Fig. 9, indicates that MSc in RegCM-UW respond appropriately to changes in synoptic-scale forcing. Additionally, the comparison of low cloud coverage (which is mostly MSc in this region) between RegCM-UW and ISCCP shows that RegCM successfully models the time evolution of MSc at diurnal, annual, interannual, and even decadal scales. While the gross properties of MSc in RegCM-UW still need work (e.g. modeled CWP is too low, low cloud fraction is too high), these results present RegCM-UW as a nascent mesoscale MSc modeling system appropriate for MSc studies ranging from synoptic to decadal time scales. 
While the addition of the UW model definitely improves RegCM and adds new capabilities, it is also clearly still a work in progress. The results from this study suggest that the following areas could use further investigation and development: (1) addition of a shallow cumulus parametrization may improve the representation of the diurnal cycle, (2) improvement of the cloud fraction parametrization may improve the representation of cloud-climate feedbacks, and (3) improvement of the autoconversion parametrization might improve precipitation biases in the model. If RegCM is to eventually be used in aerosol-cloud studies, it will also be necessary to improve the microphysics parametrization in RegCM.

On a more practical note, we are currently working with collaborators at ICTP to include the UW model in an official public release of $\operatorname{RegCM}^{10}$ (freely available under the GNU license). We anticipate that this will be released by the time that this manuscript is published, but if not, the lead author of this manuscript would be happy to share the RegCM-UW source code upon request.

In summary, the results in this manuscript show that the addition of the UW turbulence closure model adds a stratocumulus-modeling capability to RegCM. As with RegCM with the Holtslag boundary layer model, RegCMUW is appropriate for general regional climate simulations. Additionally, RegCM-UW is an appropriate tool for use in mesoscale stratocumulus studies at a wide range of temporal scales. Furthermore, the model's success in modeling cloud base height strongly suggests that the model may be an appropriate tool for studying the dominant feature of California coastal climate: fog.

Acknowledgements. The authors would like to extend their deep gratitude to Christopher Bretherton of the University of Washington for kindly sharing his turbulence closure model code with us. The authors would also like to thank two anonymous referees whose insightful comments greatly improved this manuscript. This material is based upon work supported by the National Science Foundation under Grant Numbers ATM-0533482-001 and ATM-0736046-001. This work was partially supported by a grant from the California Energy Commission. This research was partially supported by the Director, Office of Science, Office of Biological and Environmental Research of the US Department of Energy under Contract No. DE-AC02-05CH11231 as part of the Regional and Global Climate Modeling Program (RGCM). Figures were prepared using the NCAR Command Language (NCL, 2012).

Edited by: P. Jöckel

${ }^{10} \mathrm{RegCM}$ is available at http://gforge.ictp.it/gf/project/regcm/

\section{References}

Adler, R. F., Huffman, G. J., Chang, A., Ferraro, R., Xie, P.-P., Janowiak, J., Rudolf, B., Schneider, U., Curtis, S., Bolvin, D., Gruber, A., Susskind, J., Arkin, P., and Nelkin, E.: The Version-2 Global Precipitation Climatology Project (GPCP) Monthly Precipitation Analysis (1979-Present), J. Hydrometeor., 4, 11471167, 2003.

Bretherton, C. S. and Park, S.: A New Moist Turbulence Parameterization in the Community Atmosphere Model, J. Climate, 22, 3422-3448, 2009.

Bretherton, C. S. and Wyant, M. C.: Moisture Transport, LowerTropospheric Stability, and Decoupling of Cloud-Topped Boundary Layers, J. Atmos. Sci., 54, 148-167, 1997.

Bretherton, C. S., McCaa, J. R., and Grenier, H.: A New Parameterization for Shallow Cumulus Convection and Its Application to Marine Subtropical Cloud-Topped Boundary Layers, Part I: Description and 1D Results, Mon. Weather Rev., 132, 864-882, 2004a.

Bretherton, C. S., Uttal, T., Fairall, C. W., Yuter, S. E., Weller, R. A., Baumgardner, D., Comstock, K., Wood, R., and Raga, G. B.: The Epic 2001 Stratocumulus Study, B. Am. Meteorol. Soc., 85, 967977, 2004b.

Briegleb, B. P.: Delta-Eddington Approximation for Solar Radiation in the NCAR Community Climate Model, J. Geophys. Res., 97, 7603-7612, 1992.

Burk, S. D. and Thompson, W. T.: The Summertime Low-Level Jet and Marine Boundary Layer Structure along the California Coast, Mon. Weather Rev., 124, 668-686, 1996.

Clement, A. C., Burgman, R., and Norris, J. R.: Observational and Model Evidence for Positive Low-Level Cloud Feedback, Science, 325, 460-464, 2009.

Dawson, T. E.: Fog in the California redwood forest: ecosystem inputs and use by plants, Oecologia, 117, 476-485, 1998.

Dickinson, R., Henderson-Sellers, A., and Kennedy, P.: BiosphereAtmosphere Transfer Scheme (BATS) Version 1e as Coupled to the NCAR Community Climate Model, Tech. rep., NCAR/TN387+STR, 1993.

Dorman, C. E., Holt, T., Rogers, D. P., and Edwards, K.: LargeScale Structure of the June-July 1996 Marine Boundary Layer along California and Oregon, Mon. Weather Rev., 128, 16321652, 2000.

Evan, A. T., Heidinger, A. K., and Vimont, D. J.: Arguments against a physical long-term trend in global ISCCP cloud amounts, Geophys. Res. Lett., 34, L04701, doi:10.1029/2006GL028083, 2007.

Giorgi, F., Marinucci, M. R., and Bates, G. T.: Development of a Second-Generation Regional Climate Model (RegCM2). Part I: Boundary-Layer and Radiative Transfer Processes, Mon. Weather Rev. 121, 2794-2813, 1993.

Giorgi, F., Coppola, E., Solmon, F., Mariotti, L., Sylla, M., Bi, X., Elguindi, N., Diro, G. T., Nair, V., Giuliani, G., Cozzini, S., Guettler, I., O’Brien, T. A., Tawfik, A., Shalaby, A., Zakey, A., Steiner, A., Stordal, F., Sloan, L., and Brankovic, C.: RegCM4: Model description and preliminary tests over multiple CORDEX domains, Clim. Rev., 52, 7-29, doi:10.3354/cr01018, 2012.

Grell, G.: Prognostic Evaluation of Assumptions Used by Cumulus Parameterizations, Mon. Weather Rev., 121, 764-787, 1993.

Grenier, H. and Bretherton, C. S.: A Moist PBL Parameterization for Large-Scale Models and Its Application to Subtropical Cloud-Topped Marine Boundary Layers, Mon. Weather Rev., 
129, 357-377, 2001.

Holtslag, A. and Boville, B.: Local Versus Nonlocal BoundaryLayer Diffusion in a Global Climate Model, J. Climate, 6, 18251842, 1993.

Holtslag, A. A. M., De Bruijn, E. I. F., and Pan, H.-L.: A High Resolution Air Mass Transformation Model for Short-Range Weather Forecasting, Mon. Weather Rev., 118, 1561-1575, 1990.

Hubanks, P. A., King, M. D., Platnick, S., and Pincus, R.: MODIS Atmosphere L3 Gridded Product Algorithm Theoretical Basis Document, ATBD MOD-30, NASA, available at: http://modis-atmos.gsfc.nasa.gov/_docs/L3_ATBD_2008_12_ 04.pdf (last access: 1 August 2012), 2008.

Kanamitsu, M., Ebisuzaki, W., Woollen, J., Yang, S.-K., Hnilo, J. J., Fiorino, M., and Potter, G. L.: NCEP-DOE AMIP-II Reanalysis (R-2), B. Am. Meteorol. Soc., 83, 1631-1643, 2002.

Kiehl, J. T., Hack, J. J., Bonan, G. B., Boville, B., Briegleb, B. P., Williamson, D. L., and Rasch, P.: Description of the NCAR Community Climate Model (CCM3), CGD, Tech. rep., NCAR TN420+STR, 1996.

Klein, S. A. and Hartmann, D. L.: The Seasonal Cycle of Low Stratiform Clouds, J. Climate, 6, 1587-1606, 1993.

Köhler, M.: Improved prediction of boundary layer clouds, ECMWF Newsletter, Reading, United Kingdom, 104, 18-22, 2005.

Koračin, D., Lewis, J., Thompson, W. T., Dorman, C. E., and Businger, J. A.: Transition of Stratus into Fog along the California Coast: Observations and Modeling, J. Atmos. Sci., 58, 1714-1731, 2001.

Kueppers, L. M., Snyder, M. A., Sloan, L. C., Zavaleta, E. S., and Fulfrost, B.: Modeled regional climate change and California endemic oak ranges, Proc. Nat. Aca. Sci. USA, 102, 16281-16286, 2005.

Lauer, A., Wang, Y., Phillips, V. T. J., McNaughton, C. S., Bennartz, R., and Clarke, A. D.: Simulating marine boundary layer clouds over the Eastern Pacific in a regional climate model with doublemoment cloud microphysics, J. Geophys. Res., 114, D21205, doi:10.1029/2009JD012201, 2009.

Lauer, A., Hamilton, K., Wang, Y., Phillips, V. T. J., and Bennartz, R.: The Impact of Global Warming on Marine Boundary Layer Clouds over the Eastern Pacific-A Regional Model Study, J. Climate, 23, 5844-5863, 2010.

Leung, L. R., Qian, Y., Bian, X., Washington, W. M., Han, J., and Roads, J. O.: Mid-Century Ensemble Regional Climate Change Scenarios for the Western United States, Climatic Change, 62, 75-113, 2004.

Lilly, D. K.: Models of cloud-topped mixed layers under a strong inversion, Q. J. Roy. Meteor. Soc., 94, 292-309, 1968.

Lin, W., Zhang, M., and Loeb, N. G.: Seasonal Variation of the Physical Properties of Marine Boundary Layer Clouds off the California Coast, J. Climate, 22, 2624-2638, 2009.

Liu, Y. and Daum, P. H.: Parameterization of the Autoconversion Process, Part I: Analytical Formulation of the Kessler-Type Parameterizations, J. Atmos. Sci., 61, 1539-1548, 2004.

Liu, Y., Daum, P. H., McGraw, R., and Wood, R.: Parameterization of the Autoconversion Process, Part II: Generalization of Sundqvist-Type Parameterizations, J. Atmos. Sci., 63, 11031109, 2006.

Lock, A. P., Brown, A. R., Bush, M. R., Martin, G. M., and Smith, R. N. B.: A New Boundary Layer Mixing Scheme. Part
I: Scheme Description and Single-Column Model Tests, Mon. Weather Rev., 128, 3187-3199, 2000.

Martin, G. M., Bush, M. R., Brown, A. R., Lock, A. P., and Smith, R. N. B.: A New Boundary Layer Mixing Scheme, Part II: Tests in Climate and Mesoscale Models, Mon. Weather Rev., 128, 3200-3217, 2000.

McCaa, J. R. and Bretherton, C. S.: A New Parameterization for Shallow Cumulus Convection and Its Application to Marine Subtropical Cloud-Topped Boundary Layers. Part II: Regional Simulations of Marine Boundary Layer Clouds, Mon. Weather Rev., 132, 883-896, 2004.

Meehl, G. A., Stocker, T. F., Collins, W. D., Friedlingstein, P., Gaye, A. T., M.Gregory, J., Kitoh, A., Knutti, R., Murphy, J. M., Noda, A., Raper, S. C. B., Watterson, I. G., Weaver, A. J., and Zhao, Z.-C.: Climate Change 20007: The Physical Science Basis. Contribution of Working Group I to the Fourth Assessment FReport of the Intergovernmental Panel on Climate Change, chap. Global Climate Projections, Cambridge University Press, Cambridge, United Kingdom and New York, NY, USA, 747-845, 2007.

Mitchell, T. D. and Jones, P. D.: An improved method of constructing a database of monthly climate observations and associated high-resolution grids, Int. J. Climatol., 25, 693-712, 2005.

NCL: The NCAR Command Language (Version 5.2.1), Software, Boulder, Colorado: UCAR/NCAR/CISL/VETS, available at: http://dx.doi.org/10.5065/D6WD3XH5, 2012.

Nicholls, S. and Turton, J. D.: An observational study of the structure of stratiform cloud sheets: Part II, Entrainment, Q. J. Roy. Meteor. Soc., 112, 461-480, 1986.

Norris, J. R.: Interannual and Interdecadal Variability in the Storm Track, Cloudiness, and Sea Surface Temperature over the Summertime North Pacific, J. Climate, 13, 422-430, 2000.

Norris, J. R. and Leovy, C. B.: interannual Variability in Stratiform Cloudiness and Sea Surface Temperature, J. Climate, 7, 19151925, 1994.

O'Brien, T. A., Daniels, B., Snyder, M. A., Stauffer, H., Uzilov, K., and Sloan, L. C.: Technical Note: An Objective Method for Determining Ground and Vegetation Albedo in RegCM, Atmos. Chem. Phys. Discuss., in preparation, 2012.

Oleson, K. W., Niu, G.-Y., Yang, Z.-L., Lawrence, D. M., Thornton, P. E., Lawrence, P. J., Stöckli, R., Dickinson, R. E., Bonan, G. B., Levis, S., Dai, A., and Qian, T.: Improvements to the Community Land Model and their impact on the hydrological cycle, J. Geophys. Res., 113, G01021, doi:10.1029/2007JG000563, 2008.

Pal, J., Small, E., and Eltahir, E.: Simulation of regional-scale water and energy budgets: Representation of subgrid cloud and precipitation processes within RegCM, J. Geophys. Res.-Atmos., 105, 29579-29594, 2000.

Pal, J. S., Giorgi, F., Bi, X., Elguindi, N., Solomon, F., Gao, X., Francisco, R., Zakey, A., Winter, J., Ashfaq, M., Syed, F., Bell, J. L., Diffenbaugh, N. S., Karmacharya, J., Konare, A., Martinez, D., da Rocha, R. P., Sloan, L. C., and Steiner, A.: The ICTP RegCM3 and RegCNET: Regional Climate Modeling for the Developing World, B. Am. Meterol. Soc., 88, 1395-1409, 2007.

Park, S. and Bretherton, C. S.: The University of Washington Shallow Convection and Moist Turbulence Schemes and Their Impact on Climate Simulations with the Community Atmosphere Model, J. Climate, 22, 3449-3469, 2009.

Rahn, D. A. and Garreaud, R.: Marine boundary layer over the subtropical southeast Pacific during VOCALS-REx - Part 1: Mean 
structure and diurnal cycle, Atmos. Chem. Phys., 10, 4491-4506, doi:10.5194/acp-10-4491-2010, 2010a.

Rahn, D. A. and Garreaud, R.: Marine boundary layer over the subtropical southeast Pacific during VOCALS-REx - Part 2: Synoptic variability, Atmos. Chem. Phys., 10, 4507-4519, doi:10.5194/acp-10-4507-2010, 2010b.

Reynolds, R. W., Rayner, N. A., Smith, T. M., Stokes, D. C., and Wang, W.: An Improved In Situ and Satellite SST Analysis for Climate, J. Climate, 15, 1609-1625, 2002.

Rossow, W. B. and Schiffer, R. A.: Advances in Understanding Clouds from ISCCP, B. Am. Meteorol. Soc., 80, 2261-2288, 1999.

Schiffer, R. A. and Rossow, W. B.: The International Satellite Cloud Climatology Project (ISCCP): The First Project of the World Climate Research Programme, B. Am. Meteorol. Soc., 64, 779-784, 1983.

Snyder, M. A., Sloan, L. C., Diffenbaugh, N. S., and Bell, J. L.: Future climate change and upwelling in the California Current, Geophys. Res. Lett., 30, 1823-1827, 2003.

Steiner, A. L., Tonse, S., Cohen, R. C., Goldstein, A. H., and Harley, R. A.: Influence of future climate and emissions on regional air quality in California, J. Geophys. Res., 111, D18303, doi:10.1029/2005JD006935, 2006.

Stevens, B. and Feingold, G.: Untangling aerosol effects on clouds and precipitation in a buffered system, Nature, 461, 607-613, 2009.

Stevens, B., Lenschow, D. H., Vali, G., Gerber, H., Bandy, A., Blomquist, B., Brenguier, J.-L., Bretherton, C. S., Burnet, F., Campos, T., Chai, S., Faloona, I., Friesen, D., Haimov, S., Laursen, K., Lilly, D. K., Loehrer, S. M., Malinowski, S. P., Morley, B., Petters, M. D., Rogers, D. C., Russell, L., Savic-Jovcic, V., Snider, J. R., Straub, D., Szumowski, M. J., Takagi, H., Thornton, D. C., Tschudi, M., Twohy, C., Wetzel, M., and Zanten, M. C. v.: Dynamics and Chemistry of Marine StratocumulusDYCOMS-II, B. Am. Meteorol. Soc., 84, 579-593, 2003.

Stevens, B., Moeng, C.-H., Ackerman, A. S., Bretherton, C. S., Chlond, A., Roode, S. d., Edwards, J., Golaz, J.-C., Jiang, H., Khairoutdinov, M., Kirkpatrick, M. P., Lewellen, D. C., Lock, A., Stevens, Frank Müller, D. E., Whelan, E., and Zhu, P.: Evaluation of Large-Eddy Simulations via Observations of Nocturnal Marine Stratocumulus, Mon. Weather Rev., 133, 1443-1462, 2005.
Tawfik, A. B. and Steiner, A. L.: The role of soil ice in landatmosphere coupling over the United States: A soil moistureprecipitation winter feedback mechanism, J. Geophys. Res., 116, D02113, doi:10.1029/2010JD014333, 2011.

Taylor, K. E.: Summarizing multiple aspects of model performance in a single diagram, J. Geophys. Res., 106, 7183-7192, 2001.

Tennekes, H.: A Model for the Dynamics of the Inversion Above a Convective Boundary Layer, J. Atmos. Sci., 30, 558-567, 1973.

Troen, I. B. and Mahrt, L.: A simple model of the atmospheric boundary layer; sensitivity to surface evaporation, Bound.-Lay. Meteorol., 37, 129-148, 1986.

von Storch, H., Langenberg, H., and Feser, F.: A Spectral Nudging Technique for Dynamical Downscaling Purposes, Mon. Weather Rev., 128, 3664-3673, 2000.

Wang, Y., Xie, S.-P., Xu, H., and Wang, B.: Regional Model Simulations of Marine Boundary Layer Clouds over the Southeast Pacific off South America. Part I: Control Experiment, Mon. Weather Rev., 132, 274-296, 2004a.

Wang, Y., Xu, H., and Xie, S.-P.: Regional Model Simulations of Marine Boundary Layer Clouds over the Southeast Pacific off South America, Part II: Sensitivity Experiments, Mon. Weather Rev., 132, 2650-2668, 2004b.

Wang, Y., Xie, S.-P., Wang, B., and Xu, H.: Large-Scale Atmospheric Forcing by Southeast Pacific Boundary Layer Clouds: A Regional Model Study, J. Climate, 18, 934-951, 2005.

Wood, R. and Bretherton, C. S.: On the Relationship between Stratiform Low Cloud Cover and Lower-Tropospheric Stability, J. Climate, 19, 6425-6432, 2006.

Wyant, M. C., Wood, R., Bretherton, C. S., Mechoso, C. R., Bacmeister, J., Balmaseda, M. A., Barrett, B., Codron, F., Earnshaw, P., Fast, J., Hannay, C., Kaiser, J. W., Kitagawa, H., Klein, S. A., Köhler, M., Manganello, J., Pan, H.-L., Sun, F., Wang, S., and Wang, Y.: The PreVOCA experiment: modeling the lower troposphere in the Southeast Pacific, Atmos. Chem. Phys., 10, 4757-4774, doi:10.5194/acp-10-4757-2010, 2010. 